\begin{abstract}
We develop a simple model for studying the impact of monetary and fiscal policies on aggregate demand, at the business cycle frequencies. We focus on two questions principally. First, what are the key properties of the joint optimal simple rules governing the conduct of the systematic components of monetary and fiscal policy? Second, following Blanchard (1985) we construct an index of fiscal stance to disentangle the 'expenditure' and wealth effects of fiscal policy. We find that underpinning the so-called 'Taylor principle' is a fiscal policy maker giving full force to automatic stabilizers. We also find that the Mundellian assignment of policy instruments may have attractive properties.
\end{abstract}

JEL Classification: E21; E32; E52; E63.

Keywords: Optimal Simple Rules, Monetary and Fiscal Policy, Finite Lives 


\title{
Optimal Simple Rules for the Conduct of Monetary and Fiscal Policy
}

\author{
Jagjit S. Chadha ${ }^{1}$ \\ University of Cambridge \\ and \\ Charles Nolan ${ }^{2} 3$ \\ University of Durham
}

\section{Introduction}

Monetary economics has recently revived its interest in the analysis of interest rate rules for the conduct of monetary policy (Clarida, Gali and Gertler 1999). At an empirical level, interest rate rules have been shown to provide plausible characterizations of actual monetary policy across a number of countries (Taylor 1999). Also, in theoretical models with nominal rigidities and imperfect competition such rules can contribute in important ways to ensuring macroeconomic stability (Woodford 2000). But much influential analysis of optimal monetary policy has proceeded without considering the fiscal arm of macroeconomic policy. ${ }^{4}$ In this paper, we therefore explore macroeconomic policy within the context of joint plans for monetary and fiscal policy. Specifically, we examine the characteristics of the optimal simple rules for the interest rate and the fiscal surplus as they would be set by one representative policymaker. ${ }^{5}$

It is clear that monetary policy has been emphasized as the senior partner in the search for optimal stabilization rules. In particular, there is now a vast literature on desirable

\footnotetext{
${ }^{1}$ Clare College, Cambridge. Address: Department of Applied Economics, Austin Robinson Building, Sidgwick Avenue, University of Cambridge, Cambridge CB3 9DE, UK. Tel: +44 1223 335242. E-mail: jagjit.chadha@econ.cam.ac.uk. http://www.econ.cam.ac.uk/dae/people/chadha/

${ }^{2}$ Department of Economics and Finance, 23/26 Old Elvet, Durham DH1 3HY. Tel +44 1913747273. E-mail: Charles.Nolan@durham.ac.uk. http://www.dur.ac.uk/charles.nolan/index.html.

${ }^{3}$ Corresponding author. We should like to thank for useful comments on this research, Matthew Canzoneri, Sugata Gosh, Dale Henderson, Andrew Hughes Hallett, Campbell Leith, Bennett McCallum, Patrick Minford, Gabriel Talmain, Mike Wickens, Simon Wren-Lewis and conference participants at Cardiff University and York University. All remaining errors are due to the authors.

${ }^{4} \mathrm{~A}$ good point of departure is the Monetary Policy Rule Homepage set up by John Taylor, http://www.stanford.edu/ johntayl/PolRulLink.htm, which lists a large number of papers for which the effects of fiscal policy are implicit or ignored. Taylor $(1997,1999 \mathrm{~b})$ himself provides an exception to this tendency to ignore fiscal policy. However, he does not consider the joint determination of monetary and fiscal policy.

${ }^{5}$ This perspective is obviously simplified, but may not be wildly at odds with reality. In the UK, for example, a senior Finance ministry official observes the deliberations of the Bank of England's Monetary Policy Committee. The Committee is itself kept closely informed on fiscal plans. Indeed both fiscal and monetary policy are set according to plans to which policymakers have openly committed themselves; a Golden Rule for fiscal expenditure and an Inflation Target for monetary policy-where both rules were devised by the current Chancellor of the Exchequer (Finance Minister).
} 
simple rules for the conduct of monetary policy. ${ }^{6}$ The 'Taylor Rule' is an important example of such an optimal simple rule:

$$
R_{t}=R_{t}^{*}+\alpha\left(\pi_{t}-\pi^{*}\right)+\beta\left(y_{t}-y_{t}^{*}\right) .
$$

$R_{t}$ denotes the period nominal interest rate, which is the instrument of monetary policy, $R_{t}^{*}$ is a measure of the equilibrium nominal interest rate and comprises the natural real rate and the inflation target, $\left(\pi_{t}-\pi^{*}\right)$ measures the deviation of current inflation, $\pi_{t}$, from target, $\pi^{*}$, and $\left(y_{t}-y_{t}^{*}\right)$ is the deviation of output, $y_{t}$, from target, $y_{t}^{*}$. In addition, it will generally be the case that $\alpha \geq 1$, and $0 \leq \beta<1$. The first parametric restriction is known as the Taylor principle (Woodford, 1999), and the second would typically see $\beta$ somewhat closer to zero than unity. Indeed some economists have argued that $\beta$ should be identically zero at all dates and in all states (e.g., Christiano and Gust, 1999).

It is of course highly doubtful that the Taylor rule literally describes what monetary policy-makers actually do. Central bankers collect and model huge amounts of data ahead of interest rate decisions. Indeed, it is arguably the case that the feedback variables in (1.1) are not accurately observed contemporaneously with the interest rate decision. Nevertheless, over the recent past, and across a number of countries, the Taylor rule does seem to capture much of the variation in the actual interest rate. The implication seems to be that what the Taylor rule captures is 'good' monetary policy. ${ }^{7}$ And it is this ability to summarize good monetary policy that has led to many researchers incorporating such rules in quantitative general equilibrium business cycle models.

However, there have been few attempts to analyze analogous rules jointly for both monetary and fiscal policy. Of course, it would hardly be accurate to suggest that the interaction of monetary and fiscal policy has not received much attention. On the one hand, there is a large literature following the concerns raised in Sargent and Wallace (1981). That literature focuses on the results of game theoretic interactions that may arise if monetary and fiscal authorities play a 'game of chicken' with the public finances. More recently, there has been the debate surrounding fiscal theories of the price-level. ${ }^{8}$ Finally, there is also a growing literature pursuing the Ramsey-inspired approach to monetary and fiscal policy (see, for example, Lucas and Stokey, 1983, and more recently Khan, King and Wolman, 2000).

On the other hand, however, the role that the automatic fiscal stabilizers - the systematic component of fiscal policy - might play in smoothing the business cycle has received significantly less attention from quantitative theorists. The lack of attention is surprising partly because there would seem to be widespread agreement that the automatic stabilizers provide a useful role in smoothing the effects of the business cycle, e.g., Eichenbaum (1997) and Blanchard (2000) and also because of on-going debate on

\footnotetext{
${ }^{6}$ See, for example, Taylor (1999).

${ }^{7}$ See, for example, the comments and discussion in King (1999).

${ }^{8}$ See for example Woodford (2000) and McCallum (2001) for opposing views on the resulting implications for nominal determinacy.
} 
policy initiatives that would seek to limit fluctuations in the per period fiscal deficit. For example, in the USA there is continuing discussion about a Balanced Budget Amendment and in Europe the Pact for Stability and Growth is a clear attempt to impose some form of upper bound on fiscal deficits ${ }^{9}$. So, if the automatic stabilizers provide a quantitatively significant channel for stabilizing aggregate demand, ${ }^{10}$ the key question is: 'How much variation in the deficit is desirable?'.

Taylor (1999b) has recently suggested that in the US the cyclical component of fiscal policy can be well captured by a simple rule analogous to his rule for monetary policy:

$$
s_{t}=s^{*}+\gamma\left(y_{t}-y_{t}^{*}\right) \text {. }
$$

Here $s_{t}$ denotes the surplus-GDP ratio, $s^{*}$ is a measure of the trend level of that magnitude, and $\gamma=0.5$. Taylor (op. cit.) argues that permitting this systematic component of fiscal policy to operate stabilizes the economic cycle, and that discretionary changes in fiscal policy over and above these automatic responses are, in general, undesirable.

In this paper we analyze rules of the form of (1.1) and (1.2) jointly. To do so, we shall construct a model in which both monetary and fiscal policy have leverage over aggregate demand and ask what are the joint optimal rules for stabilizing the economy. In particular, we shall adopt a criterion function for the policymaker of the form, $L=L\left[\left(\pi_{t}-\pi^{*}\right),\left(y_{t}-y_{t}^{*}\right), \ldots\right]$, and investigate the constellation of parameters in rules analogous to (1.1) and (1.2) such that $(\alpha, \beta, \gamma)=\arg \min L=L\left[\left(\pi_{t}-\pi^{*}\right),\left(y_{t}-y_{t}^{*}\right), \ldots\right]$. In our model monetary policy operates principally via the standard channel of setting shortterm real interest rates and thereby tilting the planned path of agents' consumption. Fiscal policy operates via two channels: (i) wealth effects from outstanding government debt, and (ii) the aggregate effect of government expenditure. We shall assume that all government expenditure is financed out of lump-sum taxation. This is partly for simplification, but also because the stabilizers themselves are often lump sum in nature. In addition, it means that the only reason Ricardian Equivalence fails in our model is because of the probability of death assumption, and hence we can assess the impact of the wealth effect of outstanding bonds.

The paper is laid out as follows. In the next section we set out the model and discuss the construction of our aggregate equations. In section 3 we establish our simple rules for the conduct of monetary and fiscal policy. The rule for fiscal policy enables the government to issue debt, raising some modelling issues pertaining to the class of fiscal regime under investigation, and hence equilibrium selection. In section 4 we discuss these issues and show how we limit ourselves to a class of Ricardian fiscal policies (in the sense of Woodford, 2000). In section 5 we discuss the algorithm for solving the model for the optimized coefficients on our monetary-fiscal rules. Section 6 provides the results of our simulations for alternative versions of our simple rules, and what happens if one arm of

\footnotetext{
${ }^{9}$ Eichengreen and Wyplosz (1998) is an interesting discussion of these issues.

${ }^{10}$ And there is evidence that this is indeed the case, see Auerbach and Feenberg (2000) Taylor (1999b), Cohen and Follette (2000) and Blanchard (2000).
} 
policy behaves in a non-optimal manner. In section 7 we construct an index of fiscal stance (in the manner of Blanchard, 1985) and investigate the quantitative significance of the wealth effect associated with outstanding government debt. Section 8 offers some conclusions and suggests some directions for future research.

\section{The Model}

\subsection{The Representative Agent}

The model is constructed around the perpetual youth set up of Yaari (1965) and Blanchard (1985). Following Cardia (1991) and Chadha and Nolan (2001, 2002b) we convert the model into a discrete-time framework ${ }^{11}$. We assume that there are a large number of identical agents in each cohort, and we assume that the size of each cohort dies away through time. The utility function for a representative agent, $j$, is given by,

$$
V_{0}=\sum_{t=0}^{\infty}\left\{\left(\frac{1}{1+\delta}\right)^{t}\left(\frac{1}{1+\lambda}\right)^{t} E_{0} U\left(C_{t}^{j}, \frac{M_{t}^{j}}{P_{t}}, L_{t}^{j}\right)\right\} .
$$

Here $\delta$ is the subjective discount rate and $\lambda$ the time-invariant probability of death. This means that the expected remaining lifetime of any agent is equal to $\lambda^{-1}$, hence the reason why the model is dubbed the 'perpetual youth' model. The utility function is assumed to be concave and separable in its arguments, $C$, consumption, $M / P$, real money balances, where $M$ is nominal money balances and $P$ is the economy-wide pricelevel and $L$ is leisure, which is equal to $1-N$. We normalize available time to unity and so $N$ is interpretable as labor effort. In practice we shall assume log-separability, that is, $U(\cdot) \equiv\left[\log C_{t}^{j}+\log \left(\frac{M_{t}^{j}}{P_{t}}\right)+\log \left(1-N_{t}^{j}\right)\right]$ as this facilitates the construction of our aggregate equations. The representative agent maximizes expected utility subject to a sequence of per period flow constraints:

$$
(1+\lambda) M_{t-1}^{j}+(1+\lambda) B_{t-1}^{j}+W_{t} N_{t}^{j}+\Pi_{t}-T_{t} \geq P_{t} C_{t}^{j}+M_{t}^{j}+\frac{B_{t}^{j}}{1+i_{t}},
$$

where, $P_{t} C_{t}^{j}=\int_{0}^{1} p_{t}(z) c_{t}^{j}(z) d z$, and where (2.2) holds for all $t \geq 0$, and in each state of nature, $M_{-1}^{j}$ and $B_{-1}^{j}$ given. Let $z$ index goods in the economy. Then, we have that $c_{t}^{j}(z)$ denotes the representative agent's consumption of good $(z)$. In addition, $W_{t}$ denotes the nominal wage, $\Pi_{t}$ denotes profits remitted from firms where each agent receives a pooled dividend, $T_{t}$ denotes lump sum taxes, which are constant across cohorts, and $i_{t}$ is the economy-wide one-period nominal interest rate. The evolution of financial wealth, $F$, is given by

\footnotetext{
${ }^{11}$ Leith and Wren-Lewis (2000) develop a continuous time version of a closely related model.
} 


$$
F_{t}^{j}=(1+\lambda) M_{t-1}^{j}+(1+\lambda) B_{t-1}^{j}
$$

where $B_{t}$ denotes the nominal stock of bonds held over at the end of period $t-1$. The sequence of equations (2.2) together with the transversality condition, $\lim _{T \rightarrow \infty}\left(\frac{1}{1+\lambda}\right)^{T} E_{0} \prod_{j=0}^{T-1}\left(1+i_{t+j}\right)^{-1} W_{t+T}^{j} \rightarrow 0$ help ensure that the agent's optimization problem is well behaved. We note that this latter condition is weighted by the probability of death. Consumption is defined over the Dixit-Stiglitz aggregator function,

$$
C_{t}^{j} \equiv\left[\int_{0}^{1} c_{t}^{j}(z)^{\frac{\theta-1}{\theta}} d z\right]^{\frac{\theta}{\theta-1}}
$$

with the aggregate price-level derived accordingly as:

$$
P_{t} \equiv\left[\int_{0}^{1} p_{t}(z)^{1-\theta} d z\right]^{\frac{1}{1-\theta}}
$$

\subsection{Optimality conditions}

Let $\left\{\mu_{t}\right\}_{t=0}^{\infty}$ be a (state-dependent) temporal sequence of Lagrange multipliers. At each date and in each state the following equations, (2.6)-(2.9), are amongst requirements for an interior optimum:

$$
\begin{gathered}
\left(\frac{1}{1+\lambda}\right)^{t} \frac{1}{P_{t} C_{t}}=\mu_{t} \\
\left(\frac{1}{1+\lambda}\right)^{t} \frac{1}{M_{t}}+\left(\frac{1}{1+\delta}\right)(1+\lambda) E_{t} \mu_{t+1}=\left(\frac{1}{1+\lambda}\right)^{t} \mu_{t} ; \\
\left(\frac{1}{1+\lambda}\right)^{t} \frac{1}{1-N_{t}}=\mu_{t} W_{t} \\
\mu_{t}=\left(1+i_{t}\right)(1+\lambda)\left(\frac{1}{1+\delta}\right) E_{t} \mu_{t+1} .
\end{gathered}
$$

Using equations (2.6) and (2.9) in (2.7) uncovers the money demand relation:

$$
\frac{M_{t}}{P_{t}}=C_{t}\left(\frac{1+i_{t}}{i_{t}}\right)
$$


(2.6) and (2.9) imply the consumption Euler equation:

$$
E_{t} P_{t+1} C_{t+1}=\frac{1+i_{t}}{1+\delta} P_{t} C_{t}
$$

The labor supply function results from (2.6) and (2.8):

$$
N_{t}=1-C_{t}\left(\frac{W_{t}}{P_{t}}\right)^{-1} .
$$

The probability of death does not appear to 'distort' the optimality conditions (other than the transversality condition). The reason for this is straightforward. We are here following the assumptions made by Blanchard (1985) to the effect that insurance companies pay premiums to savers in return for their wealth in the event of death. This wealth is then returned lump-sum to the currently alive. Consequently, the market interest rate incorporates this 'premium', which just offsets the probability of death uplift in the agent's discounting of future utility.

\subsection{The Representative Firm}

We assume that there are a large number of infinitely-lived monopolistically competitive firms, who use only labor in the production of their differentiated good. ${ }^{12}$ Each period these firms receive a symmetric productivity shock. So for firm $i$ the production function is given by

$$
Y_{i, t}=A_{t} N_{i, t}^{\alpha}
$$

where $0<\alpha<1$, and $A_{t}$ is the productivity innovation. The firm hires labor in competitive markets and following Blanchard (1985) we assume that all agents are equally productive. Consequently, the real wage, $W_{t} / P_{t}$, is the same across all cohorts, and is given by,

$$
\frac{W_{t}}{P_{t}} \equiv w_{t}=\alpha A_{t} N_{i, t}^{\alpha-1}
$$

We further assume that firms face Calvo-type restrictions in setting prices but that firms meet demand whether or not they have been able to change prices that period. The demand for the $i^{t h}$ product is given by

$$
c_{t}(i)=\left(\frac{p_{t}(i)}{P_{t}}\right) Y_{t}^{d}
$$

where $Y_{t}^{d}$ denotes aggregate demand, the sum of private expenditure and government expenditure. In the model we develop there will be an effect directly from government

\footnotetext{
${ }^{12}$ Incorporating capital into the current set-up poses few problems. However, we are partly concerned to uncover the quantitative significance of outstanding bonds on private consumption and including a private or public capital stock would make that task somewhat more difficult.
} 
expenditure and indirectly via the stock of outstanding net bonds. The latter effect as we demonstrate below is captured in the measure of private consumption demand. A cost-minimizing firm required to meet current demand will hire labor according to the following optimality condition,

$$
w_{t}=\Lambda_{t}\left(\partial Y_{i, t} / \partial N_{i, t}\right)
$$

where $\Lambda_{t}$ measures real marginal cost. Total per-period profits then are given by

$$
\Pi_{t}(i)=p_{t}(i)\left(\frac{p_{t}(i)}{P_{t}}\right)^{-\theta} Y_{t}^{d}-\Lambda_{t}\left(\frac{p_{t}(i)}{P_{t}}\right)^{-\theta} Y_{t}^{d} .
$$

As regards price setting behavior we follow Calvo (1983) and many subsequent analysts (e.g., Yun 1996, Woodford 1997, King and Wolman 1996) and assume that firms which set prices in period $t$ face a probability, $\alpha(0 \leq \alpha<1)$ of having to live with the same decision next period. More generally, we assume that a firm which sets its price this period faces the probability $\alpha^{k}$ of having to charge the same price in $k$-periods time. The optimal price, $\tilde{p}_{t}$, is given by: ${ }^{13}$

$$
\tilde{p}_{t}=\frac{\theta \sum_{k=0}^{\infty}\left(\alpha \beta^{\prime}\right)^{k} E_{t}\left(\mu_{t+k}^{a} P_{t+k}^{\theta} Y_{t+k}^{d} \Lambda_{t+k}\right)}{(\theta-1) \sum_{k=0}^{\infty}\left(\alpha \beta^{\prime}\right)^{k} E_{t}\left(\mu_{t+k}^{a} P_{t+k}^{\theta-1} Y_{t+k}^{d}\right)} .
$$

Here $\mu_{t+k}^{a}$ is a measure of aggregate marginal utility, and $\beta=\beta^{\prime}(1+\lambda)^{-1}$. The optimal price is determined by a constant mark up, and the discounted stream of current and expected real marginal cost and demand conditions in which that price may obtain.

\subsection{Aggregation}

We turn first to the aggregate analogs to equations (2.10)-(2.12). We note that the size of the cohort born each period is given by

$$
\left(\frac{\lambda}{1+\lambda}\right)\left(\frac{1}{1+\lambda}\right)^{t}
$$

As a result of this, the size of the cohort decreases monotonically with time, and the sum of all currently alive cohorts is equal to unity. That is,

$$
\frac{\lambda}{1+\lambda} \sum_{j=-\infty}^{t}\left(\frac{1}{1+\lambda}\right)^{(t-j)}=1 \text {. }
$$

This makes aggregating the model, for the most part, straightforward. In particular, for any variable $x_{t}^{a}$ (which denotes aggregate $x$ ) it follows that,

$$
x_{t}^{a}=\frac{\lambda}{1+\lambda} \sum_{s=-\infty}^{t}\left(\frac{1}{1+\lambda}\right)^{t-s} x_{t} .
$$

\footnotetext{
${ }^{13}$ The details of this problem are well understood, and we leave them to an appendix, available upon request.
} 
For any variable $x_{t}$ the reader should note that we actually mean $x_{s, t}$ i.e., the variable $x$ pertaining to cohort $s$ at time $t$. ( $s$ therefore denotes the time period in which the cohort came into existence.) Let us pass this aggregator through the money demand equation:

$$
\frac{\lambda}{1+\lambda} \sum_{s=-\infty}^{t}\left(\frac{1}{1+\lambda}\right)^{t-s}\left(\frac{M_{t}}{P_{t}}\right)=\left(\frac{1+i_{t}}{i_{t}}\right) \frac{\lambda}{1+\lambda} \sum_{s=-\infty}^{t}\left(\frac{1}{1+\lambda}\right)^{t-s} C_{t} .
$$

However, given our definition of an aggregate variable, this means simply that

$$
\left(\frac{M_{t}}{P_{t}}\right)^{a}=C_{t}^{a}\left(\frac{1+i_{t}}{i_{t}}\right)
$$

Again, consider the labor supply function. Since the real wage is constant across cohorts we have that:

$$
\frac{\lambda}{1+\lambda} \sum_{s=-\infty}^{t}\left(\frac{1}{1+\lambda}\right)^{t-s} N_{t}=1-\left(\frac{W_{t}}{P_{t}}\right)^{-1} \frac{\lambda}{1+\lambda} \sum_{s=-\infty}^{t}\left(\frac{1}{1+\lambda}\right)^{t-s} C_{t} .
$$

Or more simply,

$$
N_{t}^{a}=1-C_{t}^{a}\left(\frac{W_{t}}{P_{t}}\right)^{-1}
$$

Aggregate consumption is given by

$$
E_{t} P_{t+1} C_{t+1}=\left(1+i_{t}\right) \beta P_{t} C_{t}-\lambda \phi E_{t} F_{t+1} .
$$

This last expression is, of course, identical to (2.11) in the event that $\lambda=0$ at each date and in each state of nature. The derivation of (2.22) is straightforward, but somewhat laborious so we have relegated it to the Appendix.

Given our assumption of infinitely lived firms, aggregation here is more straightforward. Dropping the $i$ index, equation (2.13) describes aggregate output, (2.14) describes the marginal product of labor, whilst the evolution of the aggregate price-level is given by a weighted average of this period's optimal price (common to all firms) and last period's aggregate price level:

$$
P_{t}=\left[(1-\alpha) \tilde{p}_{t}^{1-\theta}+\alpha P_{t-1}^{1-\theta}\right]^{1 /(1-\theta)} .
$$

\section{Monetary and Fiscal Policy}

We turn now to consider the aggregate policy rules in place. We shall consider the policymaker as setting the per period interest rate and net taxes-the systematic components of policy- in order to stabilize both output and inflation. That is, we are envisaging policy rules of the following sort:

$$
i_{t}=\phi\left(Y_{t}, \pi_{t}, i_{t-1}\right)
$$


and

$$
T_{t}=\psi\left(G_{t}, T_{t-1}, \gamma B_{t-1}\right)
$$

where $i_{t}$ is the nominal interest rate set in period $t, Y_{t}$ is real aggregate output, $\pi_{t}$ is the inflation rate in period $t$, and $T_{t}$ are the period lump sum taxes. Following much of the recent literature, we model monetary policy as control over the short-term (one-period) nominal interest rate. In the presence of (some) sticky prices that implies some leverage over interest sensitive endogenous variables. In our model that means essentially private consumption, although there are other effects too. ${ }^{14}$ While the monetary rule is fairly standard the rule for tax needs some explanation. We take the process for government expenditure as exogenous. We shall assume that the fiscal authority sets taxes in response to the level of contemporaneous government expenditure, that seigniorage is returned lump-sum to the private sector, and crucially that taxes respond to the level of debt outstanding at the start of the period. The parameter $\gamma$ indicates the proportion of debt that is retired each period. This ability of the government to issue debt raises some modelling issues, as the recent debate concerning the fiscal theory of the price-level has emphasized, and we shall briefly discuss these in the next section.

\section{The Government Budget}

We shall assume that the government follows a Ricardian fiscal policy. That is, regardless of the sequences of the model's other endogenous variables, the government intends to ensure that its present value budget constraint is met identically at each date and in each state of nature. In our set up the government need not run a balanced budget each period, and hence may be issuing or retiring debt. We constrain fiscal policy however to be working systematically to retire outstanding debt. This raises the issue, therefore, as to whether our debt retirement program is sufficiently robust. In particular, consider the public sector budget constraint at time $t$,

$$
\frac{B_{t}}{\left(1+i_{t}\right)}=B_{t-1}+P_{t}\left(G_{t}-T_{t}\right)-\left(M_{t}-M_{t-1}\right) \text {. }
$$

Further, consider the following parameterization of the process governing taxes,

$$
T_{t}=\chi_{t} G_{t}-\frac{\left(M_{t}-M_{t-1}\right)}{P_{t}}+\gamma \frac{B_{t-1}}{P_{t}} .
$$

Together these two equations imply that real debt, $b_{t}$, will evolve in the following manner,

$$
\frac{b_{t}}{1+r_{t}}=(1-\gamma) b_{t-1}+\left(1-\chi_{t}\right) G
$$

\footnotetext{
${ }^{14}$ For example, the real interest rate influences the net wealth of outstanding bonds. This channel appears to be of second order importance.
} 
where $r_{t}$ is the real interest rate. Hence if we define $\left(1-\chi_{t}\right) G_{t}$ as the per period deficit, $D_{t}$, then at some point, $t=T$, in the future this implies that

$$
E_{t} \frac{b_{t+T}}{\prod_{j=0}^{T}\left(1+r_{t+j}\right)}=(1-\gamma)^{T+1} b_{t-1}+E_{t} \sum_{s=0}^{T} \prod_{j=0}^{s-1}\left(\frac{1}{1+r_{t+j}}\right)(1-\gamma)^{T-s} D_{t+s} .
$$

For policy to be Ricardian we require that $E_{t} \frac{b_{t+T}}{\prod_{j=0}^{T}\left(1+r_{t+j}\right)}$, tends to zero as a result of fiscal actions and regardless of the sequence of prices and interest rates that we see. As $T \rightarrow \infty$, the first term on the right hand side does indeed tend to zero. The second magnitude measures the present discounted sequence of net debt issue looking forward from time $t$. Even in our simple set-up it is fairly difficult to say anything too precise about the required size of this parameter ${ }^{15}$. Very loosely speaking, for policy to be Ricardian we require that $\gamma$ eventually becomes and remains sufficiently large across states of nature. We investigated this issue numerically and found that $\gamma=0.06$ is a lower bound on this value. For values less than this, the model generated multiple solution paths, some of which were consistent with fiscally determined price-levels/inflation rates (as in Woodford, 1996).

\section{Parameterization of Model}

We briefly outline the key baseline parameter values that we adopt for the calibration of the model developed in section 2 and 3.

Table 1: Calibration parameters for quarterly model

\begin{tabular}{lll}
\hline \hline Symbol & Value & Description \\
\hline$\lambda$ & 0.00357 & Expected life remaining: 70 years \\
$r$ & 0.0125 & Real interest rate \\
$\beta$ & 0.95 & Subjective discount factor \\
$\delta$ & 0.053 & Subjective discount rate \\
$\gamma$ & 0.06 & Rate of debt retirement \\
$\frac{c}{y}$ & 0.6 & Steady-state consumption-output ratio \\
$\frac{m}{w}$ & 0.1 & Steady-state money-wealth ratio \\
$\kappa$ & 0.5 & Phillips curve slope \\
$\frac{w}{c}$ & 0.7 & Steady-state wealth-consumption ratio \\
\hline \hline
\end{tabular}

The model is calibrated at a quarterly frequency using more or less standard parameter values. We assume that $\lambda$ is determined as a result of the representative agent expecting to live to 70 . The discount factor, $\beta$, is set at 0.95 . As noted above, numerical investigations led us to set the debt retirement rate, $\gamma$, to 0.06 . We further assume that the steady state

\footnotetext{
${ }^{15}$ In a deterministic environment, one can make more analytical headway. See Chadha and Nolan (2002e).
} 
consumption:income ratio, $c / y$, is equal to 0.6 , while the steady state money:wealth ratio, $m / w$, was chosen to be 0.1 . Roughly speaking the average size of the UK debt-to-GDP ratio over the post-war period has been some $40 \%$, although it has been falling for much of that period, one or two episodes of notable increases apart. Together with our assumption for $c / y$, implies that the steady-state wealth:income ratio for this simple model economy is 0.7. Naturally, that number is required to parameterize our consumption Euler equation.

Specifying the nature of the stochastic forces driving the economy has less precedent in the empirical literature, although important results are emerging (see, for example, Blanchard and Perotti, 1999, Burnside, Eichenbaum and Fisher, 200, Edelberg, Eichenbaum and Fisher, 1998 and Finn, 1998). Let $a_{t}, f_{t}$, and $h_{t}$ denote the log detrended processes for productivity, fiscal and monetary innovations, respectively. We then assume they can be described adequately for our purposes as follows,

$$
\left[\begin{array}{l}
a_{t} \\
f_{t} \\
h_{t}
\end{array}\right]=\left[\begin{array}{ccc}
\rho_{a} & 0 & 0 \\
0 & \rho_{f} & 0 \\
0 & 0 & \rho_{q}
\end{array}\right]\left[\begin{array}{c}
a_{t-1} \\
f_{t-1} \\
h_{t-1}
\end{array}\right]+\left[\begin{array}{c}
x_{t} \\
g_{t} \\
q_{t}
\end{array}\right],
$$

where $x_{t}, g_{t}$, and $q_{t}$ are the shocks respectively to productivity, fiscal and monetary innovations. We adopted an agnostic strategy for setting the covariation structure of the forcing variables. First we estimated Solow residuals, Taylor Rules and Fiscal rule equations on US and UK data and found little difference in the standard errors of the respective equations. ${ }^{16}$ Similarly Cardia (1991) found that the standard deviation of shocks to the monetary and fiscal processes were of similar magnitude in the US data, whilst in the German data the standard deviations of fiscal and productivity shocks were of a similar size. In practice, then, we decided simply to set $\sigma_{a}=\sigma_{f}=\sigma_{q}=0.01$. As a point of reference, a standard result in the one-sector RBC literature is that the standard deviation of a quarterly productivity innovation is about $0.007-0.008$. We experimented by re-ordering the shocks, making in turn monetary and then fiscal shocks more volatile. This had very little effect on our results.

In terms of the persistence parameters we chose the following: $\rho_{a}=0.9, \rho_{f}=0.9$, and $\rho_{q}=0$. Again, the literature on RBC models leads us to expect persistence in productivity innovations. Similarly, the literature on fiscal shocks also seems to indicate that these are persistent. Again, we experimented with differing degrees of persistence and our findings seem largely robust to quite large variations in these parameters. Our assumption that monetary shocks are not persistent reflects a common modelling choice that monetary shocks persist largely due to interest rate smoothing, the observed tendency

\footnotetext{
${ }^{16}$ The US dataset runs from 1955:1 to 2000:4: we use the Federal Funds rate as the policy instrument in the Taylor Rule; annual inflation is measured as the four quarter percentage change in the All-Items CPI; GDP in 1995 constant prices is detrended by a quadratic time trend and the Federal Government surplus or deficit is given as a proportion of GDP. For the UK: we use the base rate as the policy instrument; annual inflation is measured as the four quarter percentage change in the RPI; GDP in 1995 constant prices is detrended by a quadratic time trend and the Public Sector Cash Requirement is given as a proportion of GDP, after being seasonally adjusted by X12.
} 
for lagged interest rates to predict current interest rates. The parameter constellation and covariation structure of the forcing process are used in conjunction with the model developed to: (i) assess the responses of the aggregate economy to shocks in the forcing variables, and (ii) establish the optimal values of the choice variables in the stabilization policy rules. ${ }^{17}$

\section{Simple Rules for Fiscal and Monetary Policy}

The model developed in the previous sections can be solved for the equilibrium evolution of aggregate wealth, consumption, money holdings, labor supply, inflation, the short term nominal interest rate, the level of taxation, government interest-bearing debt and aggregate output. We outline the solution procedure by first noting that the model requires the following equations, converted into aggregate form as required: (2.3), (2.18), (2.20), (2.21), (2.22), (3.1) and (3.2), (4.1), together with an equation describing the aggregate economy-wide resource constraint. The feedback coefficients in the policy rules, equations (3.1) and (3.2), are left unspecified and we solve for these adopting a quadratic criterion for the policymaker, following Williams (1999) and Dennis $(2001)^{18}$. In practice that means we need to calculate, for a given stochastic structure for the economy's driving processes, the asymptotic variance-covariance matrix for the economy's endogenous variables. We first linearize the model around its non-stochastic steady state. Then we make an initial guess about the optimal policy parameters, given the other parametric assumptions we have made, and verify that the model admits a unique stable rational expectations equilibrium under this parameter constellation. Once we have established the existence of such an equilibrium, we are able to calculate the loss function of the policymaker. We then iterate on this calculation for alternate selections of policy rule parameter values, and compare losses, and continue in this way until a minimum for the loss function is located.

More specifically, the linearized model developed in sections 2 and 3 can be represented in compact form with all variables in percentage deviation from the steady state as

$$
A E_{t} y_{t+1}=B y_{t}+C x_{t} \quad \forall t \geq 0
$$

$y_{t}$ is a vector of endogenous variables comprising both predetermined and nonpredetermined variables including policy rules for the nominal interest rate and taxes.

\footnotetext{
${ }^{17}$ See Chadha and Nolan (2002e) for an analysis of the stability conditions for this model.

${ }^{18}$ We augment the King and Watson (1997) code to perform what is, in effect, a grid search over the policy parameters such that the policymakers loss function is minimised. Alternative code has been written by Richard Dennis (2001) to solve for optimal simple rules under rational expectations This latter algorithm, however, requires something close to what we call the $B$ matrix in (6.1) to be non-singular. For larger models that is often inconvenient since some manual system reduction is then required. Our code requires neither $A$ nor $B$ to be singular. The King and Watson (1997) reduction algorithm can deal with singular $A$ matrices whilst our method of calculating the model's asymptotic variance-coviariance matrix does not require the inversion of $B$ at any step along the way. Dennis' (2001) code however can also be used to solve for the case when precommitment is not feasible.
} 
$x_{t}$ is a vector of exogenous variables and $A, B$ and $C$ are matrices of fixed, time-invariant coefficients. $E_{t}$ is the expectations operator conditional on information available at time t. King and Watson (1998) demonstrate that if a solution to (6.1) exists and is unique then we may write such a solution in state-space form as follows:

$$
\begin{aligned}
y_{t} & =\Pi s_{t}, \\
s_{t} & =M s_{t-1}+G e_{t},
\end{aligned}
$$

where the $s_{t}$ matrix includes the state variables of the model (predetermined variables along with exogenous state variables), $e_{t}$ is a vector of shocks to the state variables and $\Pi, M$ and $G$ are coefficient matrices. The $y_{t}$ matrix has also been augmented to include the model's exogenous state variables. Let npd denote the number of predetermined variables, $n x$ the number of exogenous state variables and let nnpd denote the number of non-predetermined variables. The dimensions of our system are as follows: $y_{t}$ is $[(n n p d+n p d+n x) \times 1], s_{t}$ is $[(n p d+n x) \times 1], \Pi$ is $[(n n p d+n p d+n x) \times(n p d+n x)], M$ is $[(n p d+n x) \times(n p d+n x)]$, and $G$ is $[(n p d+n x) \times(n p d+n x)]$. We can use equations (6.2) to calculate the asymptotic variance-covariance matrix for the model's endogenous variables. ${ }^{19}$ To proceed, iterate on the second set of equations. Since there are a sufficient number of stable roots, we have

$$
s_{t}=G \sum_{j=0}^{\infty} M^{j} e_{t-j} .
$$

Using this result in the first set of equations in (6.2) we find that

$$
y_{t}=\sum_{j=0}^{\infty} \Phi M^{j} e_{t-j}
$$

where $\Phi \equiv \Pi G$ is $[(n n p d+n p d+n x) \times(n p d+n x)]$. As the stochastic shocks to the economy are assumed to be covariance stationary, it then follows that we may write,

$$
y_{t} y_{t}^{\prime} \equiv \Sigma=\sum_{j=0}^{\infty} \Phi M^{j} \Omega M^{j \prime} \Phi^{\prime},
$$

where a prime denotes a transpose and $\Omega \equiv e_{t} e_{t}^{\prime}{ }^{20}$ Using the relevant entries from the $\Sigma$ matrix finally allows us to evaluate the policymaker's loss function.

Our problem, then, is to find the set of parameter values $\Gamma=\left(\phi_{\pi}^{m}, \phi_{y}^{m}, \phi_{\pi}^{f}, \phi_{y}^{f}, \rho^{m}, \rho^{f}\right)$, where the superscript $m$ refers to the linearized interest rate rule, (3.1), the superscript $f$ refers to the linearized fiscal rule, (3.2), and where $\rho$ refers to the degree of autocorrelation in the two rules, such that the following welfare loss function is minimized:

\footnotetext{
${ }^{19}$ The interested reader should consult Hansen and Sargent (1998) for further details.

${ }^{20}$ To derive (6.5) we have used the result that for any two conformable matrices $A$ and $B,(A B)^{\prime}=B^{\prime} A^{\prime}$. Note also that since our shocks are serially uncorrelated, we have that $e_{t} e_{t-j}^{\prime}=0 \quad \forall j>0$.
} 


$$
E\left\{J_{T}\right\}=E\left\{\sum_{t=0}^{T-1} \beta^{t} L_{t}\left(y_{t} ; \Gamma\right)+\beta^{T} L_{T}\left(y_{T} ; \Gamma\right)\right\} .
$$

The policymaker's period loss function, $L$, is given by

$$
L=\alpha_{1} \Sigma_{\pi}+\alpha_{2} \Sigma_{y}+\alpha_{3} \Sigma_{i}
$$

where $\Sigma_{x}$ denotes the asymptotic variance of the annualized value of $x$, given $\Gamma{ }^{21}$

\section{Results}

We know from a vast amount of work that has taken place in recent years that a Taylor rule does well in the type of model we have developed above. Although we are not aware of an estimated Blanchard-Yaari model for which the performance of a Taylor rule has been evaluated, our aggregate equations are for the most part similar to the standard representative agent set-up, and so we presume that something like a Taylor rule remains a desirable rule for monetary policy. As important, we also know that something like a Taylor rule tracks real-world policy rates fairly closely, so that if our model is to track data on monetary policy choices it needs to generate a Taylor-like rule. What we also ask of our model, in terms of equation 3.2, is what are the optimal weights in the fiscal rule?

Recall from the literature on Taylor rules (see, for example, Woodford, 1999) that a weight of greater than unity on contemporaneous inflation and a weight close to zero on contemporaneous output has desirable stabilizing properties (see also Christiano and Gust, 1999). Our results for optimality of this simple Taylor rule are given in Table 2.

Table 2: The Simple Taylor Rule

\begin{tabular}{cccc}
\hline \hline & Interest rate rule & Fiscal rule \\
\cline { 2 - 4 }$\pi_{t}-\pi^{*}$ & 1.15 & $\pi_{t}-\pi^{*}$ & 0 \\
$y_{t}-y_{t}^{*}$ & 0.06 & $y_{t}-y_{t}^{*}$ & 1.75 \\
$R_{t-1}$ & 0.25 & $D_{t-1}$ & 0.57 \\
\hline \hline
\end{tabular}

The numbers reported in this table correspond to the optimized coefficients associated with the arguments (indicated to the left) in the reaction functions. In all of the simulation results reported we have constrained fiscal policy not to react to the inflation deviation from target. We see, then, that the Taylor principle is respected in our optimized rule, yielding an impact coefficient on inflation deviations of 1.15, and an eventual (long-run) feedback on inflation of just over 1.5: in fact, Taylor (1993) himself suggested a value of 1.5. Note also that, at the optimum, there is a weak contemporaneous feedback from output

\footnotetext{
${ }^{21}$ Following Battini et al. (2001) we assume that $\alpha_{1}=\alpha_{2}=1$, and $\alpha_{3}=0.25$.
} 
(0.06). Interest rates are autocorrelated, although to a degree that appears somewhat less than one might expect. Turning to the deficit rule, we see that the deficit reacts robustly to the output gap. The surplus:GDP ratio responds contemporaneously to the output gap with a coefficient of 0.75 (somewhat higher than Taylor's recommendation), and is more highly autocorrelated than the nominal interest rate.

Figures 9.1-9.4 illustrate the fit of the optimized rules with data from the US and the UK. The familiar charts of the Taylor Rule tracking actual policy rates in 9.1 and 9.3 are now augmented by fiscal rules. The simulated optimal simple rules provide a reasonable visual fit to the data (which are described in footnote 10 above). We are reluctant to claim too much for these simulated rules, as our model is clearly very parsimonious. For example, the simple rules result in fairly robust fiscal responses which are apparent towards the start of the sample period. In a sense, however, these two sets of charts make clear what we think is a key message of this paper: good monetary policy is predicated on good fiscal policy (and vice versa). Our set up allows us to be clear, within the confines of our model, what "good" fiscal policy looks like.

\subsection{Impulse Responses}

Before assessing a number of different policy scenarios, we discuss the impulse responses of output, interest rates, the fiscal balance and inflation to $1 \%$ shocks in each of the forcing variables given the optimized coefficients reported in Table 2. From the plots of these responses, a picture emerges of monetary and fiscal policy working as a complementary sequence of choices.

\subsubsection{Productivity shock}

Figures 9.5-9.8 outline the response of this economy to a symmetric persistent shock to productive capacity. Naturally, output responds positively and with a high degree of persistence to a productivity shock. Inflation mirrors the response, as falling marginal costs put downward pressure on firms' prices, by falling below baseline for 7 quarters. The optimal policy response involves the nominal interest rate falling below base, while the fiscal surplus rises. Nominal interest rates are cut in order to stabilize falling inflation and lump-sum taxation tempers aggregate demand.

\subsubsection{Monetary shock}

Figures 9.9-9.11 outline the response of the economy to innovations in the economy's interest rate rule. Output remains below its steady-state level for some 10 quarters, although it is within $0.1 \%$ of base after only 3 quarters. Output falls because a monetary policy shock increases real rates. Fiscal policy responds to this monetary tightening by running a (persistent) deficit. The maximal response is in the first period where the deficit increases by $0.8 \%$, which is some $0.2 \%$ greater than the fall in output. Inflation responds 
quickly to the monetary shock, falling by just under $0.5 \%$ in the first period and returns more than half way to base by period 2 .

\subsubsection{Fiscal shock}

Figures 9.12-9.14 depict the response of output, nominal interest rates and inflation to fiscal policy shocks. The fiscal impact on output operates via government expenditure and bonds and is explored explicitly in section 8 where we construct a measure of the fiscal stance. The increase in output and inflation caused by the impact on aggregate demand leads to a persistent but small rise in nominal interest rates. The effects of government expenditure are analyzed in Baxter and King (1993). Briefly, a rise in government expenditure on final goods results in a rise in labor supply which boosts aggregate output (despite pushing down on aggregate consumption).

\subsection{Policy Simulations}

In this subsection we discuss five policy experiments that flow naturally from the optimal simple rules we have already characterized. We solve for these rules using the method outlined in section 6. However, here we exogenously restrict the parameter space, $\Gamma$, allowing us to explore further the interactions between joint (constrained) optimal plans for monetary and fiscal policy.

\subsubsection{Mundellian Assignment}

First, we compare the optimized rule presented in Table 2 to that which would be implied by the implementation of Mundell's (1971) suggestion to assign policy tools where he claimed they had the greatest efficacy i.e., monetary policy to inflation and fiscal policy to output. Table 3 shows the optimal weights for such a rule are very close to the rule optimized in Table 2. We find that the long run coefficients are $\phi_{\pi}^{m}=1.3$ and $\phi_{y}^{f}=3.3$. In our set up, the Mundellian assignment results in systematic policy very close to that described in Table 2.

Table 3: Mundell Assignment Rule

\begin{tabular}{cccc}
\hline \hline & Interest rate rule (IRR) & Fiscal rule (FR) \\
$\pi_{t}-\pi^{*}$ & 1.07 & $\pi_{t}-\pi^{*}$ & - \\
$y_{t}-y_{t}^{*}$ & - & $y_{t}-y_{t}^{*}$ & 1.14 \\
$R_{t-1}$ & 0.19 & $D_{t-1}$ & 0.65 \\
\hline \hline
\end{tabular}

So the interesting supplementary question is what happens if one arm of policy 'misbehaves' or is constrained, perhaps by political forces, to behave in a sub-optimal way - at least as defined by our criterion. 
7.2.2. $\phi_{y}^{f}=0$

Let us suppose that fiscal policy, in the first instance, is constrained not to respond to output at all. Table 4 shows the resulting implications for the monetary rule.

Table 4: Taylor Rule Implications of Fiscal Deficit Smoothing

\begin{tabular}{|c|c|c|c|c|c|c|}
\hline & \multicolumn{5}{|c|}{ Interest rate rule } & Fiscal rule \\
\hline$\pi_{t}-\pi^{*}$ & 4.83 & 3.55 & 1.54 & 1.01 & $\pi_{t}-\pi^{*}$ & - \\
\hline$y_{t}-y_{t}^{*}$ & 0.80 & 0.55 & 0.19 & 0.19 & $y_{t}-y_{t}^{*}$ & - \\
\hline$R_{t-1}$ & $0 . \overline{2} 5$ & 0.3 & 0.5 & 0.8 & $D_{t-1}$ & 0.9 \\
\hline
\end{tabular}

Here we have constrained fiscal policy merely to follow an autocorrelated process. When fiscal policy does not react to output, $\phi_{y}^{f}=0$, we find that the long run coefficient on inflation in the interest rate rule moves sharply up at the optimum. The long-run coefficient on inflation, $\phi_{\pi}^{m}$ is found to be over 5 , regardless of the extent of interest rate smoothing (which we have constrained to take the values in Table 4). We note that should the policy maker wish to limit her dynamic response to inflation in the region of $1-1.5$, then in the presence of a passive fiscal stance, significant interest rate smoothing should be employed i.e. the lagged coefficient on interest rates should be above 0.5. In short, a passive fiscal policy shifts the burden of stabilization entirely onto monetary policy, causing that arm of policy to be somewhat more active than the Taylor principle might suggest.

7.2.3. $\phi_{y}^{f} \leq 0$

Table 5: Taylor Rule Implications of Procyclical Deficit Smoothing

\begin{tabular}{ccccccc}
\hline \hline & \multicolumn{7}{c}{ Interest rate rule } & Fiscal rule \\
\cline { 2 - 7 }$\pi_{t}-\pi^{*}$ & 6.17 & 10.46 & 19.35 & 49.36 & $\pi_{t}-\pi^{*}$ & - \\
$y_{t}-y_{t}^{*}$ & 1.13 & 2.08 & 4.07 & 10.77 & $y_{t}-y_{t}^{*}$ & $\phi_{y}^{f}$ \\
$R_{t-1}$ & 0.25 & 0.25 & 0.25 & 0.25 & $D_{t-1}$ & 0.8 \\
\hline Fiscal Rule $\phi_{y}^{f}$ & -0.05 & -0.10 & -0.15 & -0.20 & & \\
\hline \hline
\end{tabular}

Table 5 considers further implications for the monetary policy rule when fiscal policy is set procyclically rather than counter-cyclically. The first point to note is that for high long run negative feedback from the output gap, i.e., $\phi_{y}^{f}>0.8$, the system quickly becomes unstable. But if we allow for small negative feedback we find that the weights on both output and, in particular, inflation rise considerably in order to attain an optimum. This result implies that, to some limited extent, monetary policy can substitute for poorly designed fiscal policy by becoming significantly more aggressive. 
7.2.4. $\phi_{\pi}^{m} \rightarrow 1$

Table 6: Fiscal Policy Implications of Threshold Taylor Observance

\begin{tabular}{ccccccccccc}
\hline \hline & IRR & FR & IRR & FR & IRR & FR & IRR & FR & IRR & FR \\
\cline { 2 - 10 }$\pi_{t}-\pi^{*}$ & 0.5 & - & 0.5 & - & 0.9 & - & 0.9 & - & 0.8 & - \\
$y_{t}-y_{t}^{*}$ & 0.5 & 1.69 & 0.1 & 1.72 & 0.1 & 1.68 & 0.1 & 2.19 & 0.1 & 2.27 \\
$\rho$ & 0.5 & 0.68 & 0.5 & 0.65 & 0.5 & 0.61 & 0.2 & 0.44 & 0.2 & 0.47 \\
\hline \hline
\end{tabular}

Table 6 considers the implications for fiscal policy as the long run coefficient on inflation in the interest rate rule tends to one. ${ }^{22}$ The first two sets of results (columns 2-5) show that if the IRR maintains a long run coefficient on inflation of at least one, $\phi_{\pi}^{m} \geq 1$, optimal fiscal policy will alter little. The next three sets of results vary the long run response of the IRR to inflation, from $\phi_{\pi}^{m}=1.8,1.1$ and 1.0. We see that as the IRR response to inflation tends towards one, and given that the output response is small, the optimal FR responds to output more powerfully. This means that fiscal policy can, to some extent, act as a substitute for weak IRR responses to inflation but the policy losses at each of these optima suggest that this strategy is somewhat unattractive.

\subsubsection{Inflation Nutter}

Table 7: Fiscal Policy Implications of the 'Inflation Nutter'

\begin{tabular}{ccccccc}
\hline \hline & IRR & FR & IRR & FR & IRR & FR \\
\cline { 2 - 7 }$\pi_{t}-\pi^{*}$ & 4.5 & - & 3.5 & - & 2.0 & - \\
$y_{t}-y_{t}^{*}$ & 0.1 & 3.06 & 0.1 & 3.03 & 0.1 & 2.57 \\
$\rho$ & 0.2 & 0.44 & 0.2 & 0.47 & 0.2 & 0.52 \\
\hline \hline
\end{tabular}

Our final illustration in Table 7 shows the implications for fiscal policy from a monetary policy-maker who places a high weight on inflation stabilization. The Table shows that active monetary policy in this case engenders similarly active fiscal policy in order to reach the optimum. This means that aggressive monetary policy will be complemented by a similar fiscal policy in order to stabilize the economy optimally: aggression breeds aggression. The high weight on inflation in the monetary rule results in a volatile real interest rate, in turn generating a volatile path for consumption and hence output. Consequently this elicits a robust response from fiscal policy.

The simulations in this section have shown that (i) the Mundellian assignment strategy may have a number of attractive properties; (ii) passive fiscal policy, at the optimum, may provide a further rationale for aggressive monetary policy which itself may be engendered

\footnotetext{
${ }^{22}$ The columns headed IRR refer to Interest Rate Rule and those headed FDR refer to the Fiscal Deficit
} Rule. For IRR go to the 1.h.s. column for a key and for FDR go to the r.h.s. for a key. 
by interest rate smoothing; (iii) near breaching of the Taylor principle, in terms of the unit response of interest rates to inflation, will stimulate active fiscal policy at an optimum; and (iv) that aggressive monetary policy will again engender active fiscal policy. In each case understanding optimal monetary policy requires a characterization of the concomitant fiscal policy choices, where output stabilization seems to lie very much within the correct scope of fiscal rather than monetary policy.

In the next section, we investigate in more detail the routes by which fiscal policy stabilizes output in our economy. In particular, we turn to the quantitative importance of the wealth effect associated with bonds outstanding to inquire whether this makes a significant difference to the optimal simple rules.

\section{The Impact of Fiscal Policy}

\subsection{The index of fiscal stance}

As the work of Baxter and King (1993) and Aiyagari, Christiano and Eichenbaum (1993) makes clear, government expenditure can influence the level of aggregate demand in a flexible price competitive macroeconomic environment, even when bonds are not net wealth. Indeed, the behavior of the model economies analyzed in those papers indicates that fiscal policy has multiplier effects on output which rise in the persistence of the shock to expenditure. In our sticky-price environment, fiscal variables influence the level of aggregate demand, $Y_{t}^{d}=C_{t}+G_{t}$, at time $t$ via a number of channels. Here we follow Blanchard (1985) and construct an index of fiscal stance. Let IFS denote the 'index of fiscal stance': that is, those components of aggregate demand (both injections and withdrawals) due to fiscal policy that contribute to demand this period. So using our expression for the aggregate consumption function (see the appendix), we find that the index may be written as,

$$
\begin{aligned}
I F S_{t}= & G_{t}-\frac{1+\lambda-\beta}{1+\lambda}\left[E_{t} \sum_{s=t}^{\infty} \prod_{j=0}^{s-1}\left\{\left(\frac{1}{1+r_{t+j}}\right)\left(\frac{1}{1+\lambda}\right)^{s-t} G_{s}\right\}\right] \\
& +\frac{1+\lambda-\beta}{1+\lambda}\left[b_{t-1}+E_{t} \sum_{s=t}^{\infty} \prod_{j=0}^{s-1}\left\{\left(\frac{1}{1+r_{t+j}}\right)\left(\frac{1}{1+\lambda}\right)^{s-t}\left(G_{s}-T_{s}\right)\right\}\right],
\end{aligned}
$$

which is equivalent to equation (28) in Blanchard (1985). The first line is the effect of government expenditure on aggregate demand when it is financed out of contemporaneous taxation. The second line is the effect of financing via debt issue and represents the wealth effect of bonds. To see this distinction more clearly, recall that the government's presentvalue budget is

$$
b_{t-1}=-E_{t} \sum_{s=t}^{\infty} \prod_{j=0}^{s-1}\left\{\left(\frac{1}{1+r_{t+j}}\right)\left(G_{s}-T_{s}\right)\right\}
$$


where we have partialled out the seigniorage term. Hence the index may now be written as,

$$
\begin{aligned}
I F S_{t}= & G_{t}-\frac{1+\lambda-\beta}{1+\lambda}\left[E_{t} \sum_{s=t}^{\infty} \prod_{j=0}^{s-1}\left\{\left(\frac{1}{1+r_{t+j}}\right)\left(\frac{1}{1+\lambda}\right)^{s-t} G_{s}\right\}\right] \\
& +\frac{1+\lambda-\beta}{1+\lambda}\left[E_{t} \sum_{s=t}^{\infty} \prod_{j=0}^{s-1}\left\{\left(\frac{1}{1+r_{t+j}}\right)\left[1-\left(\frac{1}{1+\lambda}\right)^{s-t}\right]\left(G_{s}-T_{s}\right)\right\}\right] .
\end{aligned}
$$

\subsection{Wealth Effect of Bonds}

The wealth effect impacting on aggregate consumption dynamics in equation (2.22) is filtered by a parameter that represents the steady-state ratio of wealth to consumption, $\frac{w}{c}$, multiplied by the probability of death, $\lambda$. From our discussion of the IFS, in the previous sub-section, we note that if $\lambda=0$ then the second line in (8.3) is identically zero across all dates and states and bonds are not net wealth. For $\lambda \neq 0$, and $b_{t-1}>0$, outstanding bonds will tend to boost aggregate demand. In this section we therefore examine the impact on the optimal rule of allowing the probability of death to increase. In the following tables $\lambda=0.003$ implies expected remaining life is 70 years, $\lambda=0.005$ implies a horizon of 50 years and $\lambda=0.007$ implies a 35 year horizon.

Table 8: The Simple Taylor Rule for alternative $\lambda$

\begin{tabular}{cccccccc}
\hline \hline & \multicolumn{3}{c}{ Interest rate rule } & \multicolumn{3}{c}{ Fiscal rule } \\
\cline { 2 - 8 }$\lambda$ & 0.003 & 0.005 & 0.007 & & 0.003 & 0.005 & 0.007 \\
\cline { 2 - 7 }$\pi_{t}-\pi^{*}$ & 1.1502 & 1.1496 & 1.1487 & $\pi_{t}-\pi^{*}$ & 0 & 0 & 0 \\
$y_{t}-y_{t}^{*}$ & 0.0604 & 0.0592 & 0.0574 & $y_{t}-y_{t}^{*}$ & 1.7524 & 1.7524 & 1.7524 \\
$R_{t-1}$ & 0.2495 & 0.2489 & 0.2481 & $D_{t-1}$ & 0.5726 & 0.5730 & 0.5734 \\
\hline \hline
\end{tabular}

Table 9: Mundell Assignment Rule for alternative $\lambda$

\begin{tabular}{cccccccc}
\hline \hline & \multicolumn{3}{c}{ Interest rate rule } & \multicolumn{3}{c}{ Fiscal rule } \\
\cline { 2 - 8 }$\lambda=$ & 0.003 & 0.005 & 0.007 & & 0.003 & 0.005 & 0.007 \\
\cline { 2 - 8 }$\pi_{t}-\pi^{*}$ & 1.0708 & 1.0721 & 1.0739 & $\pi_{t}-\pi^{*}$ & 0 & 0 & 0 \\
$y_{t}-y_{t}^{*}$ & 0 & 0 & 0 & $y_{t}-y_{t}^{*}$ & 1.1363 & 1.1471 & 1.1634 \\
$R_{t-1}$ & 0.1893 & 0.1919 & 0.1903 & $D_{t-1}$ & 0.6492 & 0.6483 & 0.6471 \\
\hline \hline
\end{tabular}

Tables 8 and 9 show that halving life expectancy makes very little difference to the optimal weights. This is so both for the rule used in Table 2 (which corresponds to Table 8), or for the Mundellian assignment in Table 3 (corresponding to Table 9). Recall that Ricardian Equivalence fails in this set-up solely because of the overlapping generations 
structure of the model, since not all of the currently alive can expect to live sufficiently long to face the obligations of current debt creation. These results therefore tell us that the magnitude of the wealth effect does not play a crucial role in explaining the optimal degree of fiscal stabilization: the optimal weights in the fiscal rule reflect primarily the effect of government expenditure financed out of contemporaneous expenditure.

\section{Conclusions}

We develop, calibrate and simulate a micro-founded model in which prices are rigid and firms produce differentiated goods. Fiscal policy acts to influence aggregate demand by influencing current expenditure. Monetary policy regulates inflation by setting the price of intertemporal trade. At the policy optimum, we find a robust case for the policymaker observing the Taylor principle in conjunction with letting automatic stabilizers induce a non-zero fiscal balance through the economic cycle.

We show that neglect of the role of automatic stabilizers in designing optimal policy will have significant implications for optimal monetary policy. For example, we show that 'passive' fiscal policy necessitates large (i.e. $\phi_{\pi}^{m}>5$ ) long run responses to inflation in the interest rate rule. Also we indicate how aggressive monetary policy may result in an aggressive set of fiscal plans. The recent literature on monetary policy rules (e.g., Clarida, Gali and Gertler, 1999) has implicitly assumed the 'correct' fiscal policy will be followed. In this paper we have developed a model that allows is to say what form that fiscal policy takes. Our brief comparison of actual and 'optimal' policy suggests some insight has been gained, despite the simplicity of our model.

In future work, we will seek to extend the fiscal environment in two directions. First, we shall incorporate distortionary taxation. Recent work by Auerbach and Feenberg (2000) suggests that this will be an important channel through which the systematic effects of fiscal policy operate. That will also constitute an additional and likely more important channel through which Ricardian Equivalence will fail. Second, we aim to incorporate 'useful' government expenditure, perhaps via influencing the marginal return to private investment, and a distinction between government employment and government purchases. As Finn (1998) demonstrates, this latter distinction is of crucial importance, as they have offsetting impacts on ouput. Future work might also consider more rigorously the implications of non-collusive behavior between the monetary and fiscal policy makers. In this regard, an interesting application might be the implications of such behaviour to regions within a monetary union.

Finally, we noted at the start of this paper that Taylor Rules for monetary policy were unlikely to describe literally what monetary policymakers actually do. Similarly, the simple fiscal rules that we have constructed, although providing an interesting 'backof-the envelope' calculation of the magnitude of deficits and surpluses that one might want to occur in actual economies, tell us little about the micro-structure of the tax and 
benefits system. For example, different fiscal micro-structures are likely to be consistent with a given degree of variation in the aggregate surplus:GDP ratio at the business cycle frequencies. Investigating these issues is also likely to be an interesting avenue for future research.

\section{References}

[1] Auerbach, A. J. and D. Feenberg (2000), "The Significance of Federal Taxes as Automatic Stabilizers," mimeo.

[2] Batini, N., R. Harrison and S. Millard (2001), "Monetary Policy Rules for an Open Economy", Working Paper Bank of England, No. 149, December.

[3] Barro, R. J. (1974), "Are Government Bonds Net Wealth?", Journal of Political Economy, vol 82, no 6, pp 1095-1117.

[4] ___________, . (1979), "On the Determination of the Public Debt", Journal of Political Economy, vol 87, no 5, part 1, pp 940-71.

[5] Baxter, M. and R.G. King (1993). "Fiscal Policy in General Equilibrium", American Economic Review, 83(3), June 1993, pp. 315-34

[6] Blanchard O J (1985) "Debts, Deficits and Finite Horizons" Journal of Political Economy, 93, pp.223-247.

[7] ___________, (2000), "Comments on Cohen and Follette", FRBNY Economic Policy Review, April 2000, pp69-74.

[8] _ Dynamic Effects of Changes in Government Spending and Taxes on Output", NBER Working Paper No. 7269, July.

[9] Burnside, C., M. Eichenbaum and J. D. M. Fisher (2001), "Assessing the Effects of Fiscal Shocks", Mimeo.

[10] Calvo, G. A. (1983) "Staggered Prices in a Utility Maximising Framework", Journal of Monetary Economics, 12, no.3 (September), pp983-98.

[11] Canzoneri, M. B., C. Nolan and A. Yates, (1997), "Mechanisms for Achieving Monetary Stability: Inflation Targeting versus the ERM", Journal of Money Credit and Banking, 29(1), pp. 46-60.

[12] Cardia, E. (1991), "The Dynamics of a Small Open Economy in response to Monetary, Fiscal and Productivity Shocks", Journal of Monetary Economics, 28(3), pp.411-434. 
[13] Chadha, J. S., N. Janssen and C. Nolan, (2001), "Productivity and Preferences in a Small Open Economy", The Manchester School, volume 69 s1, (September), pp57-80.

[14] Chadha, J. S., and C. Nolan, (2002a), "Inflation versus Price-Level targeting in a New Keynesian Macro-model", The Manchester School.

[15] _ _ Exploration in "The Theory and Practice of Monetary Transmission in Diverse Economies" edited by P. J. Sinclair et al., Cambridge University Press.,

[16] _ _ _ _ _ _ , (2002c), "Output, Inflation and the New Keynesian Phillips Curve (2002), mimeo.

[17] Forthcoming in Dynamic Macroeconomics: Theory and Policy in General Equilibrium, edited by Sumru Altug, Jagjit Chadha and Charles Nolan, Forthcoming in 2003, Cambridge University Press. , (2002e), "The Interaction of Monetary and Fiscal Policy: When Does Aggregative Fiscal Policy Matter?" In preparation.

[19] Christiano, L.J. and Gust, C.J. (1999) "Taylor Rules in a Limited Participation Model" National Bureau of Economic Research Working Paper, 7017, March 1999, p. 17 .

[20] Clarida, R., J. Gali, and M. Gertler, (1999) "The Science of Monetary Policy: A New Keynesian Perspective", Journal of Economic Literature 37(4), December 1999,pp. 1661-1707.

[21] Christiano, L.J. and Gust, C. (1999), "Taylor Rules in a Limited Participation Model", NBER Working Papers, 7017, National Bureau of Economic Research, Inc.

[22] Cohen, D., and G. Follette (2000), "The Automatic Fiscal Stabilizers: Quietly Doing Their Thing", FRBNY Economic Policy Review, April 2000, pp35-68.

[23] Dennis, R. (2001), "Solving for Simple Rules in Rational Expectations Models", Working Paper, Federal Reserve Bank of San Francisco Number 00-14.

[24] Edelberg, W., M. Eichenbaum and J. D. M. Fisher (1998), "Understanding the Effects of a Shock to Government Purchases" University of Chicago, Mimeo.

[25] Eichenbaum, M. (1997), "Some Thoughts on Practical Stabilization Policy (in Is There a Core of Practical Macroeconomics That We Should All Believe?), The American Economic Review, Vol. 87, No. 2, Papers and Proceedings of the Hundred and Fourth Annual Meeting of the American Economic Association. (May, 1997), pp. $236-239$. 
[26] Eichengreen, B. and C. Wyplosz (1998), "Stability Pact: More than a Minor Nuisance?", Economic Policy, April 67-113.

[27] Erceg, C., D. Henderson and A. Levin, (2000), "Optimal monetary policy with staggered wage and price contracts", Journal of Monetary Economics, Vol. 46, pp 281-313.

[28] Finn, M. G. (1998), "Cylical Effects of Government's Employment and Goods Purchases", International Economic Review, Vol. 39, No. 3, pp635-657.

[29] Hansen, L. P. and Sargent, T. J. (1998), Recursive Linear Models of Dynamic Economies, Chicago: University of Chicago Press.

[30] Khan, A., R. G. King and A. L. Wolman (2000), "Optimal Monetary Policy", Federal Reserve Bank of Richmond Working Paper No. 00-10, October.

[31] King, M. (1999), "Challenges for Monetary Policy: New and Old", in New Challenges for Monetary Policy, Federal Reserve Bank of Kansas City Symposium, pp.11-57.

[32] King, R.G. and Watson, M.W. (1998). "The Solution of Singular Linear Difference Systems under Rational Expectations," International Economic Review, 39(4) pp. $1015-26$

[33] King, R. G. and A. Wollman (1996), "Inflation Targeting in a St. Louis Model of the 21st Century", Federal Reserve Bank of St. Louis Review, May/June, 1996.

[34] Leith, C. and S. Wren-Lewis (2000), "Interactions Between Monetary and Fiscal Policy Rules, Economic Journal, vol 110, No. 462, March, C93-C108.

[35] Lucas, R.E. Jr and N. L. Stokey (1983) "Optimal Fiscal and Monetary Policy in an Economy without Capital", Journal of Monetary Economics, Vol 12, pp55-93.

[36] McCallum, B. T (2001), "Indeterminacy, Bubbles and the Fiscal Theory of Price Level Determination", Journal of Monetary Economics, vol. 47, no 1, February, pp 19-30.

[37] Mundell, R.A. (1971). "The Dollar and the Policy Mix", Essays in International Finance No. 85.

[38] Sargent, T.J. and N. Wallace (1981), "Some Unpleasant Monetarist Arithmetic", FRB, Minneapolis.

[39] Taylor, J. B.,(1993), "Discretion versus Rules in Practice", Carnegie-Rochester Conference Series on Public Policy, vol. 39, pp195-214.

[40] __________, (1997), "The Policy Rule Mix: A Macroeconomic Policy Evaluation", Working Paper Stanford University. 
[41] , (1999a), Monetary Policy Rules, Chicago: University of Chicago Press, NBER.

[42] Paper Stanford University. , (1999b), "Reassessing Discretionary Fiscal Policy", Working

[43] Williams, J. C. (1999) "Simple Rules for Monetary Policy", Board of Governors of the Federal Reserve System, Finance and Economics Discussion Paper, No. 1999-12, February, Washington.

[44] Woodford, M. (1995), "Price Level Determinacy without Control of a Monetary Aggregate", Carnegie Rochester Conference Series on Public Policy, vol 43, pp 1-46.

[45] _ Stability?", in The Debt Burden and Monetary Policy, eds: G. A. Calvo, and M. A. King, ., London: MacMillan.

[46] _-_-_-_-_-_, (1998a), Public Debt and the Price Level, Princeton University, mimeo.

[47] inflation", in NBER Macroeconomics Annual, edited by Ben S. Bernanke and Julio J. Rotemberg, MIT Press, Cambridge, Massachusetts, pp 400-28.

[48] Monetary Policy, Princeton University, mimeo.

[49] Yaari, M. E. (1965), "Uncertain Lifetime, Life Insurance, and the Theory of the Consumer", Review of Economic Studies, 32 (April), pp.137-50.

[50] Yun, T. (1996), 'Nominal Price Rigidity, Money Supply Endogeneity and Business Cycles', Journal of Monetary Economics, 37, pp.345-370. 


\subsection{Appendix: Aggregate consumption dynamics}

In this appendix we derive equation (2.22) in the main text. We cannot simply pass the aggregator function through equation (2.11). In the standard representative agent framework the Euler equation captures aggregate consumption dynamics by construction. In other words, if we use the standard Euler equation and the present value budget constraint, in the infinite-lived representative agent set up, we find that aggregating across all consumers one ends up back at the simple Euler equation as an equation that also represents aggregate consumption-savings behavior. That equivalence between individual and aggregate behavior vis a vis consumption does not obtain in our set up. To see this, iterate on the consumption Euler equation and use the present value budget constraint to find that,

$$
\begin{aligned}
E_{t} \sum_{s=t}^{\infty} \prod_{j=0}^{s-1} & \left(\frac{1}{1+i_{t+j}}\right)\left(\frac{1}{1+\lambda}\right)^{s-t} P_{s} C_{s}= \\
& F_{t}+E_{t} \sum_{s=t}^{\infty} \prod_{j=0}^{s-1}\left\{\left(\frac{1}{1+i_{t+j}}\right)\left(\frac{1}{1+\lambda}\right)^{s-t}\left[W_{s} N_{s}+\Pi_{s}-T_{s}-\frac{i_{s}}{1+i_{s}} M_{s}\right]\right\},
\end{aligned}
$$

where $F_{t}=(1+\lambda) M_{t-1}+(1+\lambda) B_{t-1}$. That is, we assume that on death financial wealth is transferred via "insurance companies" as windfall dividends to currently alive agents. Our assumption of log separability means that the left hand-side of the above expression an be written as $\frac{1+\lambda}{1+\lambda-\beta} P_{t} C_{t}$, so that we have

$$
P_{t} C_{t}=\frac{1+\lambda-\beta}{1+\lambda}\left[F_{t}+E_{t} \sum_{s=t}^{\infty} \prod_{j=0}^{s-1}\left\{\begin{array}{c}
\left(\frac{1}{1+i_{t+j}}\right)\left(\frac{1}{1+\lambda}\right)^{s-t} \times \\
{\left[W_{s} N_{s}+\Pi_{s}-T_{s}-\frac{i_{s}}{1+i_{s}} M_{s}\right]}
\end{array}\right\}\right]
$$

which is the solved out consumption function for a given agent of a currently alive cohort. We now want to calculate aggregate $P_{t+1} C_{t+1}-P_{t} C_{t}$. First we economize on some notation, rewriting (9.1) as

$$
P_{t} C_{t}=\Psi\left[F_{t}+E_{t} \sum_{s=t}^{\infty} \prod_{j=0}^{s-1}\left\{\left(\frac{1}{1+i_{t+j}}\right)\left(\frac{1}{1+\lambda}\right)^{s-t} \Theta_{s}\right\}\right]
$$

where $\Psi \equiv \frac{1+\lambda-\beta}{1+\lambda}$, and $\Theta_{s} \equiv W_{s} N_{s}+\Pi_{s}-T_{s}-\frac{i_{s}}{1+i_{s}} M_{s}$. We shall also avoid carrying around expectations operators. We construct $P_{t+1} C_{t+1}-P_{t} C_{t}$ in two steps. First we derive an expression for the evolution of aggregate 'human' wealth, $\Theta_{s}$, and then we calculate an analogous expression for aggregate financial wealth. The sum of these two expressions delivers aggregate consumption dynamics. First, then, we look to the change in aggregate 'human' wealth, which will have the same form, given our assumptions, as individual 
human wealth. Hence, we have that,

$$
\begin{aligned}
& \Psi\left[\begin{array}{rr}
F_{t+1}+\Theta_{t+1}+\left(\frac{1}{1+i_{t+1}}\right)\left(\frac{1}{1+\lambda}\right) \Theta_{t+2}+ & \\
& \left.\left(\frac{1}{1+i_{t+1}}\right)\left(\frac{1}{1+i_{t+2}}\right)\left(\frac{1}{1+\lambda}\right)^{2} \Theta_{t+3}+. .\right]
\end{array}\right] \\
& -\Psi\left[F_{t}+\Theta_{t}+\left(\frac{1}{1+i_{t}}\right)\left(\frac{1}{1+\lambda}\right) \Theta_{t+1}+\left(\frac{1}{1+i_{t}}\right)\left(\frac{1}{1+i_{t+1}}\right)\left(\frac{1}{1+\lambda}\right)^{2} \Theta_{t+2}+. .\right] \text {. }
\end{aligned}
$$

Collecting terms we see that

$$
\Psi \begin{array}{r}
-\Theta_{t}+\left(1-\left(\frac{1}{1+i_{t}}\right)\left(\frac{1}{1+\lambda}\right)\right) \Theta_{t+1}+ \\
\left(1-\left(\frac{1}{1+i_{t}}\right)\left(\frac{1}{1+\lambda}\right)\right)\left(\frac{1}{1+i_{t+1}}\right)\left(\frac{1}{1+i_{t+2}}\right)\left(\frac{1}{1+\lambda}\right)^{2} \Theta_{t+3}+\ldots
\end{array}
$$

This expression can, with a little rearrangement, be rewritten as

$$
\Psi\left[\Theta_{t}+\frac{(1+\lambda)\left(1+i_{t}\right)-1}{(1+\lambda)\left(1+i_{t}\right)}\left[\sum_{s=t+1}^{\infty} \prod_{j=0}^{s-1}\left\{\left(\frac{1}{1+i_{t+j}}\right)\left(\frac{1}{1+\lambda}\right)^{s-(t+1)} \Theta_{s}\right\}\right]\right] .
$$

We now calculate an expression for $\Psi\left[F_{t+1}-F_{t}\right]$. First we recall that we now need to work with aggregate financial wealth. Since in the aggregate there can be no windfall gains, we now define $F$ as follows

$$
F_{t}=M_{t-1}+B_{t-1}
$$

Using this in the flow budget constraint we find after some manipulation that

$$
F_{t}+P_{t} C_{t}+\frac{F_{t+1}}{1+i_{t}}-\Theta_{t}
$$

Therefore the change in wealth may be written as,

$$
\Psi\left[\frac{i_{t}}{1+i_{t}} F_{t+1}+\Theta_{t}-P_{t} C_{t}\right]
$$

and combining this with expression (9.3) we get that

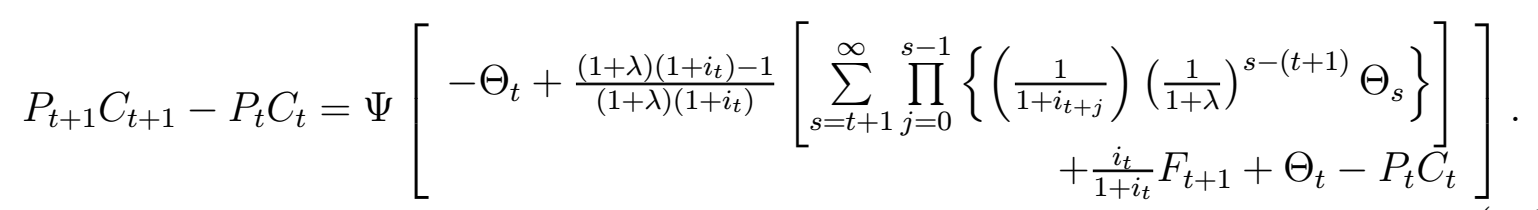

However, we already know that

$$
P_{t+1} C_{t+1}=\Psi\left[F_{t+1}+\sum_{s=t+1}^{\infty} \prod_{j=0}^{s-1}\left\{\left(\frac{1}{1+i_{t+j}}\right)\left(\frac{1}{1+\lambda}\right)^{s-(t+1)} \Theta_{s}\right\}\right],
$$


so we can re-write (9.4) as

$$
\begin{aligned}
P_{t+1} C_{t+1}-P_{t} C_{t}=\Psi\left[-\Theta_{t}+\frac{(1+\lambda)\left(1+i_{t}\right)-1}{(1+\lambda)\left(1+i_{t}\right)}\left[\frac{P_{t+1} C_{t+1}}{\Psi}-F_{t+1}\right]\right] & +\Psi\left[\frac{i_{t}}{1+i_{t}} F_{t+1}+\Theta_{t}-P_{t} C_{t}\right]
\end{aligned}
$$

And straightforward simplification results equation (2.22):

$$
E_{t} P_{t+1} C_{t+1}=\left(1+i_{t}\right) \beta P_{t} C_{t}-\lambda \phi E_{t} F_{t+1} .
$$




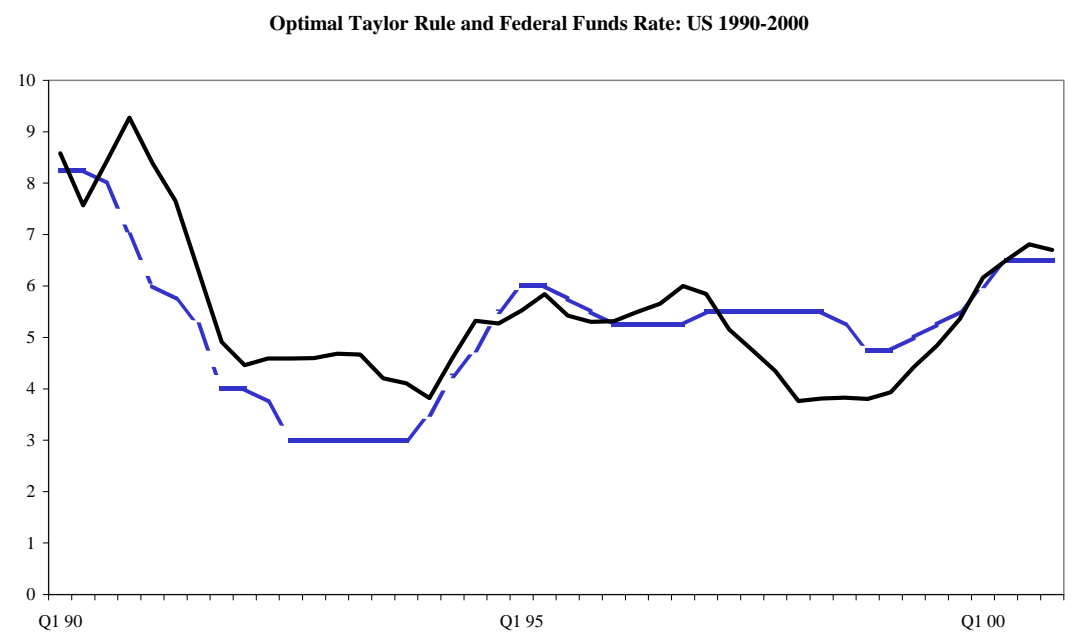

Figure 9.1:

Optimal Fiscal Rule and Fiscal Surplus: US 1990-2000

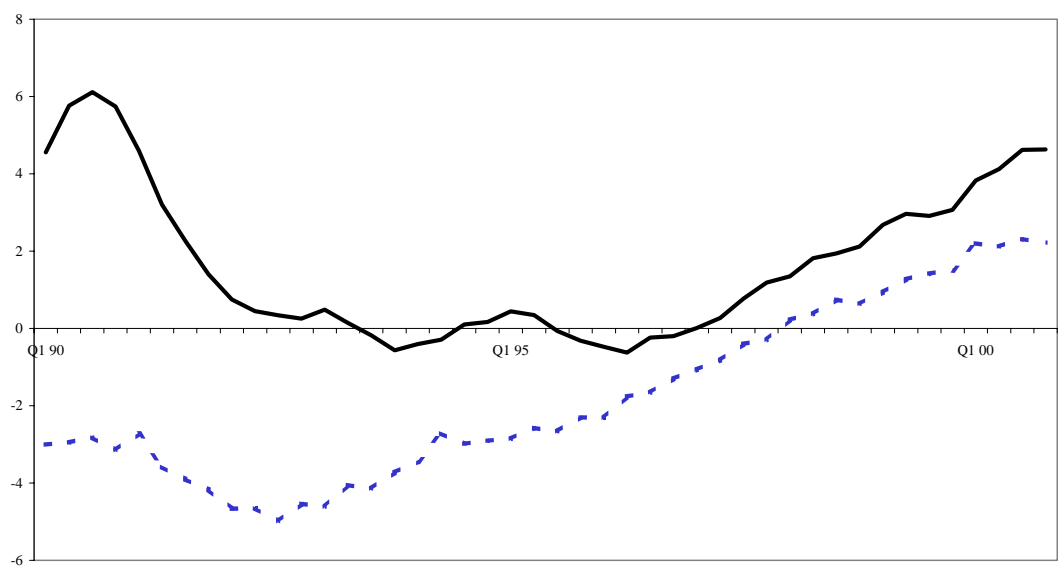

Figure 9.2: US Stabilization Policy: Actual (dotted) and Optimal (solid) 


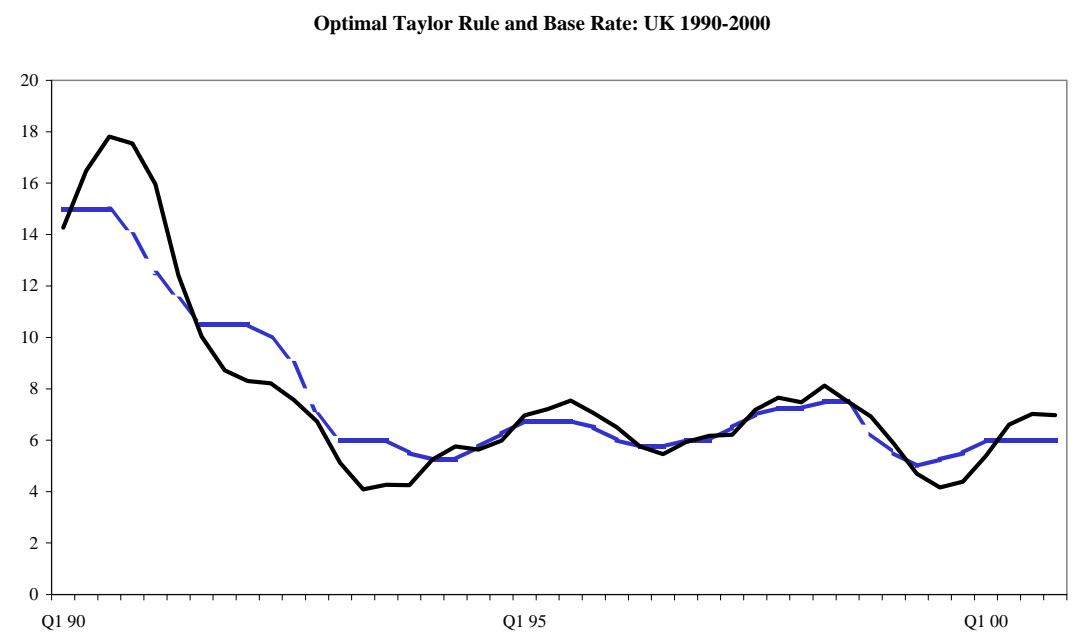

Figure 9.3:

Optimal Fiscal Rule and Budget Surplus: UK 1990-2000

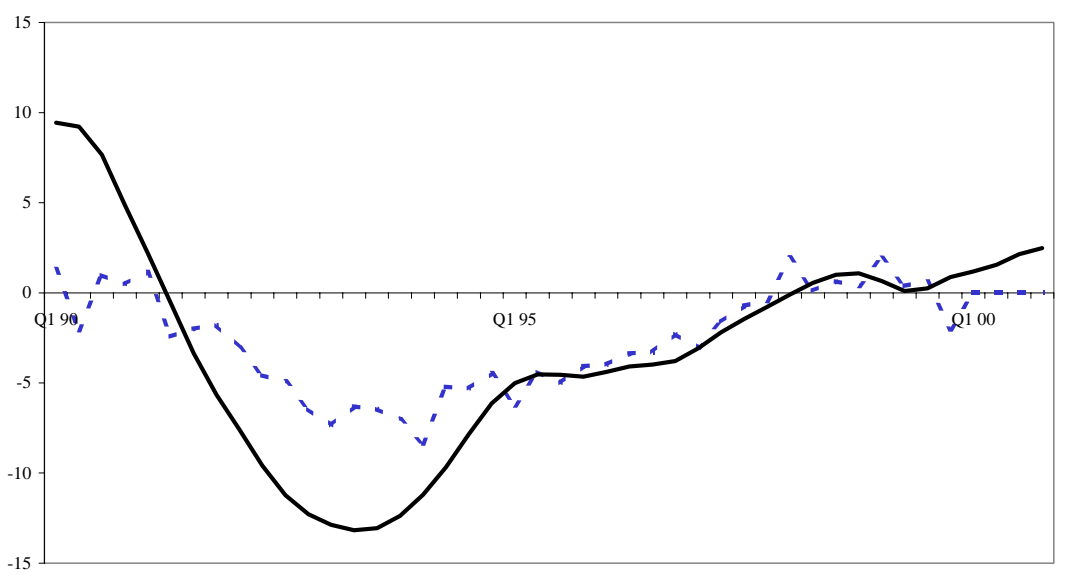

Figure 9.4: UK Stabilization Policy: Actual (dotted) and Optimal (solid) 
output in response to productivity shock

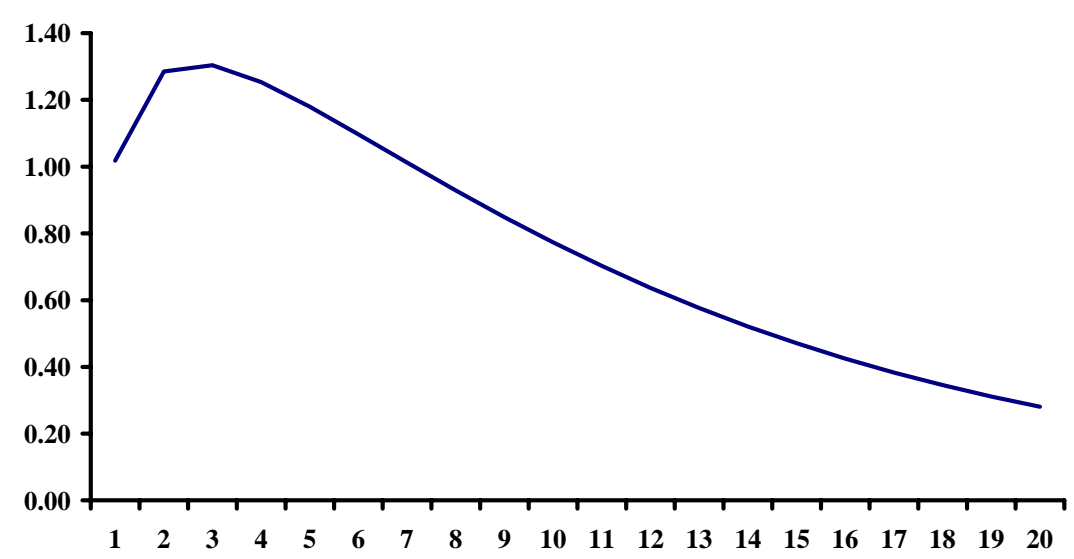

Figure 9.5:

nominal interest in response to productivity shock

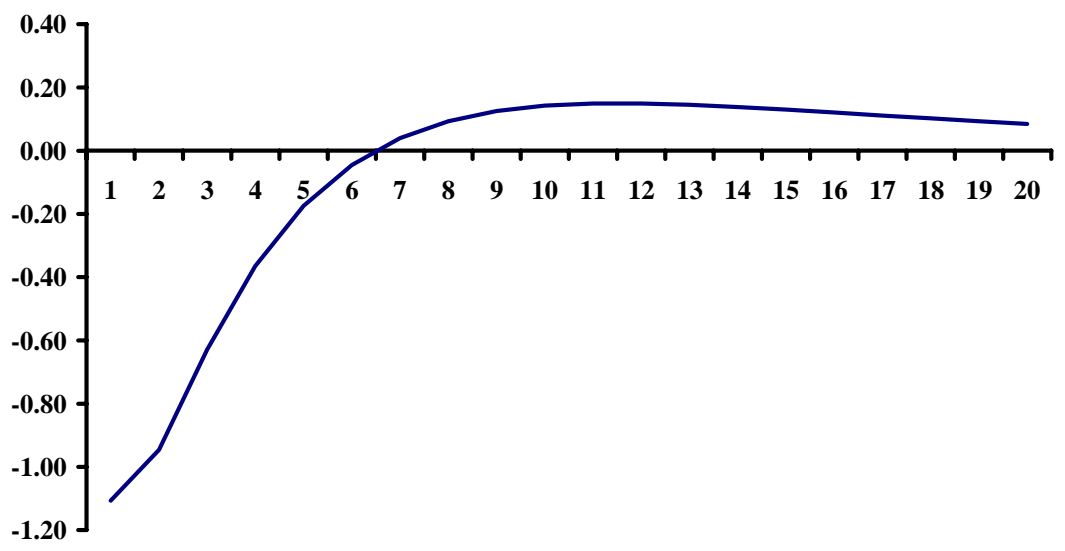

Figure 9.6: 
Surplus in response to productivity shock

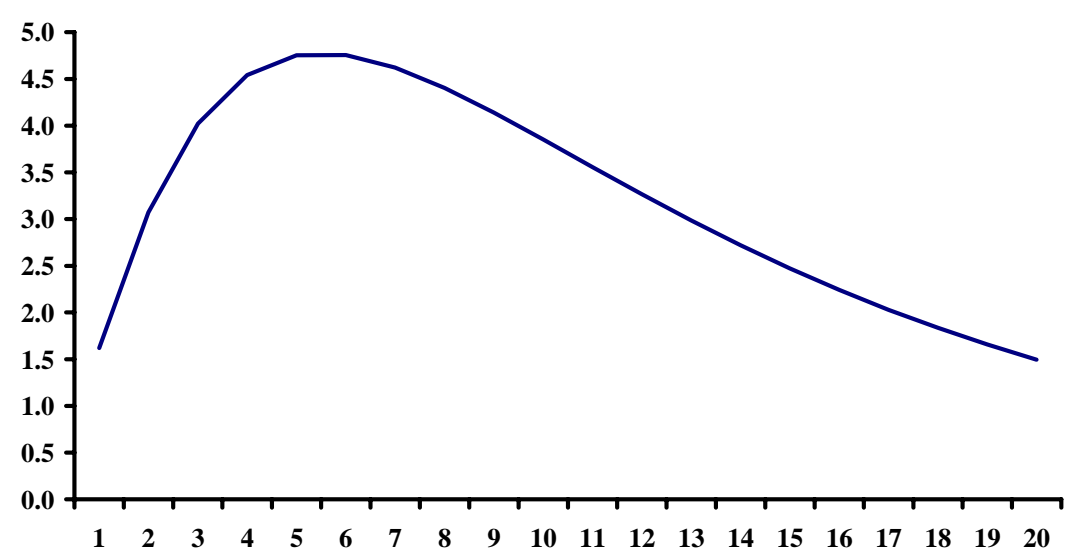

Figure 9.7:

Inflation in response to productivity shock

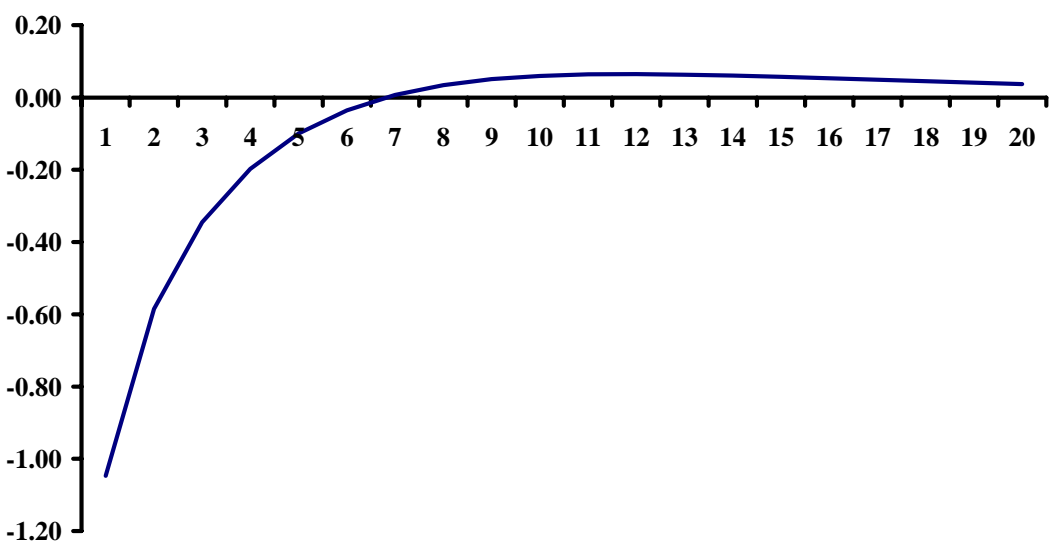

Figure 9.8: 
output in response to monetary shock

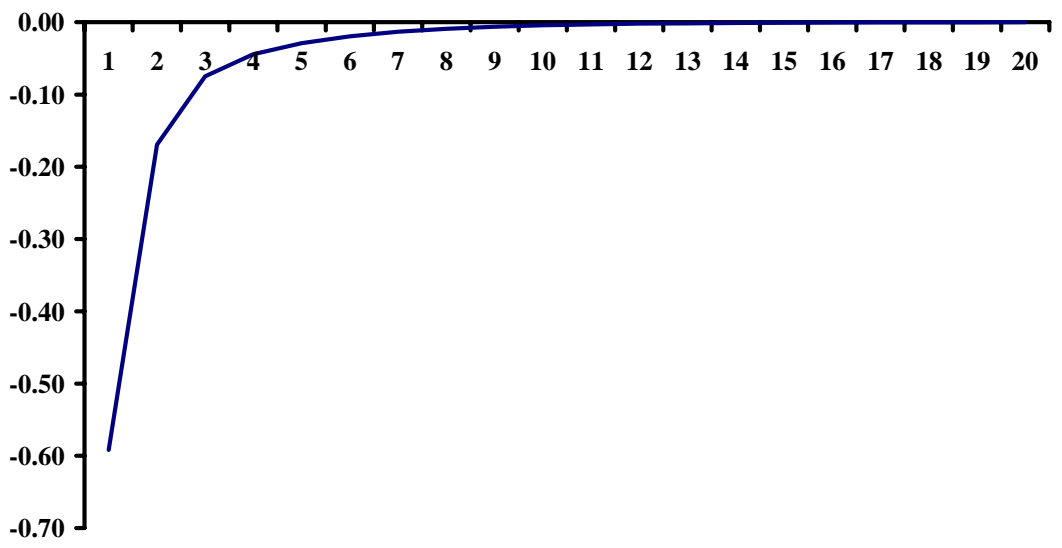

Figure 9.9:

Surplus in response to monetary shock

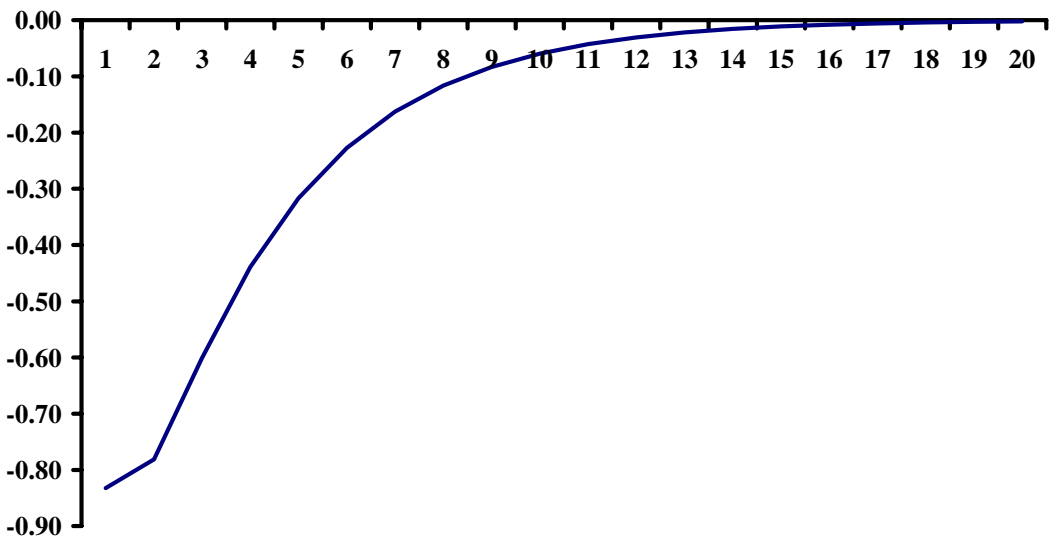

Figure 9.10: 
Inflation in response to monetary shock

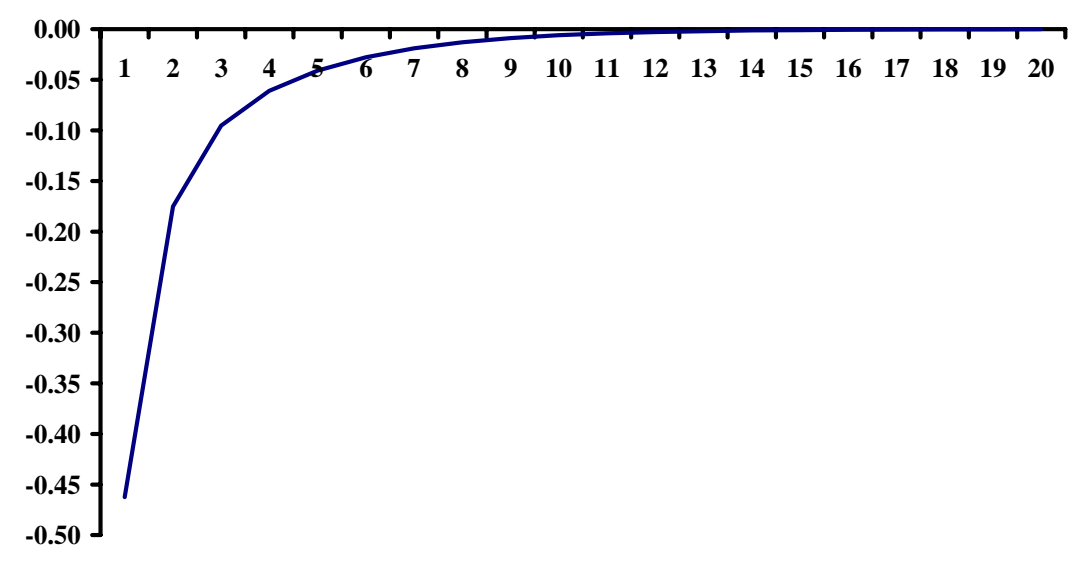

Figure 9.11:

output in response to fiscal shock

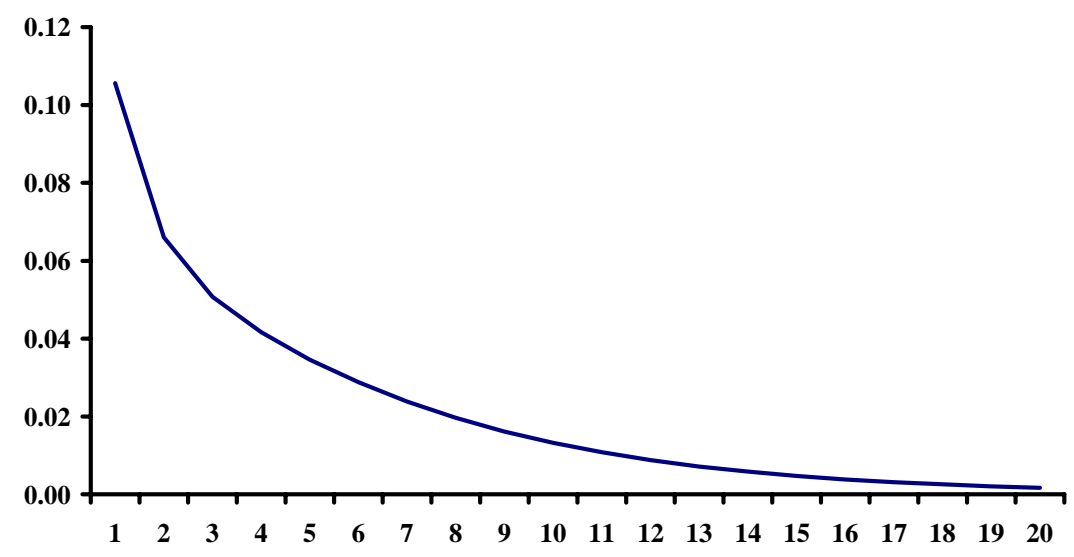

Figure 9.12: 
nominal interest in response to fiscal shock

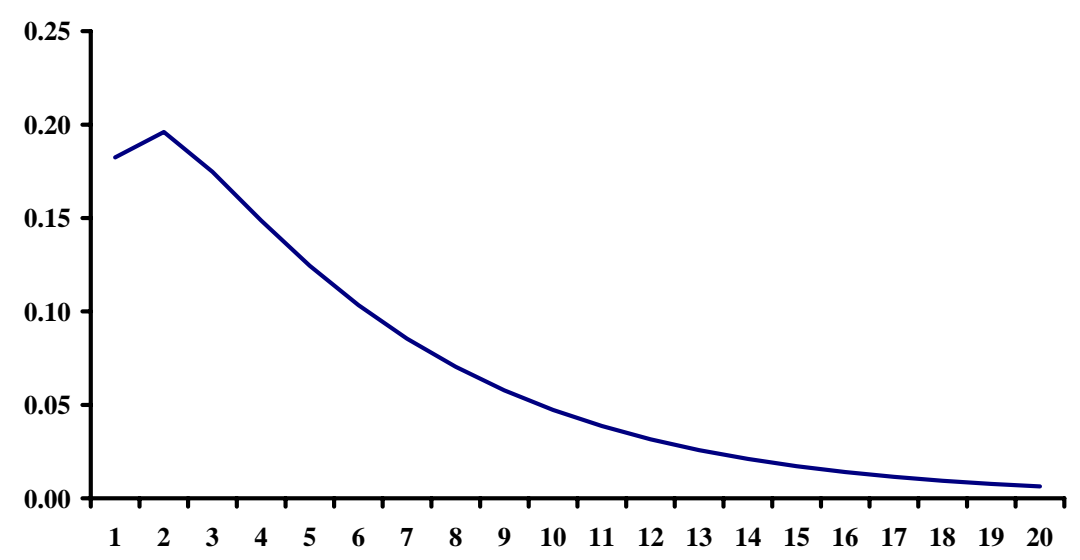

Figure 9.13:

Inflation in response to fiscal shock

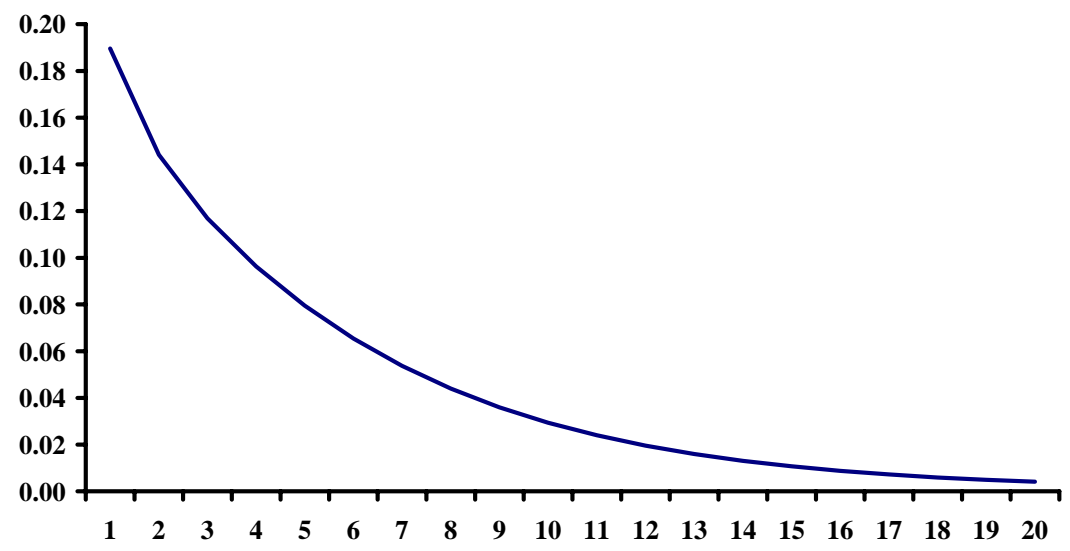

Figure 9.14: 